\title{
Técnica, áulica y distinción social en la cerámica medieval
}

\author{
Jaume Coll Conesa \\ Museo Nacional de Cerámica "González Martí" \\ jaume.coll@mecd.es
}

\section{RESUMEN}

La sociedad islámica dotó a la cerámica de una elevada capacidad de representación simbólica del poder gracias a su impulso, favorecedor de un gran desarrollo técnico. En al-Andalus ello se percibe ya en el califato de Córdoba con la introducción de la loza estannífera, pero los reinos de taifas alcanzarán una cota superior con la producción de la loza dorada. Este papel fue emulado por la sociedad cristiana promoviendo la transferencia técnica al fomentar paulatinamente el artesanado mudéjar y destinar sus producciones tanto a necesidades áulicas como de mercado.

Palabras clave: Al-Andalus, España Medieval, técnica cerámica, mayólica y loza dorada, cerámica áulica.

\section{Technique, Courtliness and Social Distinction in the Medieval Ceramics}

\begin{abstract}
Islamic society gave the pottery a high capacity for symbolic representation of power thanks to its promotion, favouring his great technical development. This can be perceived in al-Andalus during the Caliphate of Córdoba, with the introduction of tin-glaze pottery, but it achieved under taifa's kingdoms an upper bound with the lusterware. This role was emulated by Christian society promoting technical transfer and gradually impulsing the Moorish craft and using their ceramics for both, the Court and market needs.
\end{abstract}

Key words: Al-Andalus, Medieval Spain, ceramic technique, majolica, lustreware, aulic pottery. 


\section{Introducción}

Durante la Edad Media, la cerámica inició una larga tradición áulica gracias al papel destacado y al especial reconocimiento que le concedió la sociedad islámica, posteriormente emulado por los reinos cristianos. Las cerámicas que gozaron de ese poder de representación requerían para su fabricación de unos conocimientos situados en los límites de la tecnología de su tiempo, además de un largo adiestramiento de los artesanos, o al-fahhārin, para alcanzar la calidad exigida. En este artículo revisaremos algunos de los grupos técnicos de la cerámica producida en al-Andalus y en los reinos cristianos del periodo medieval hispánico, que gozaron de ese reconocimiento al proveer manufacturas de calidad al servicio de personas y estamentos de la mayor relevancia social.

En al-Andalus, tras el periodo de independencia política de la etapa emiral impulsado por la dinastía Omeya que reconocía la autoridad religiosa del califato abasí de Bagdad, nació el califato de Córdoba. Este nuevo poder autónomo político y religioso favoreció la aparición de una corte rodeada de un sistema de representación y de un protocolo que abarcaba todos los aspectos de la actividad humana. Como una más de las artes que acompañaban al refinamiento de la corte, la cerámica se desarrolló desde entonces formando parte activa del aparato de representación del sistema, tanto desde claves materiales como simbólicas. Además, la emulación de determinados aspectos del refinamiento de la corte islámica en los propios reinos cristianos, inducidos en los territorios peninsulares por la proximidad, los frecuentes contactos y la convivencia, facilitó la transmisión de bienes, técnicas y tradiciones entre ambas sociedades y estimuló el florecimiento de una loza de calidad que fue ganando más y más prestigio en su desarrollo hasta el fin de la Edad Media, ya realizada con claves iconográficas específicas de ese nuevo universo social.

La sociedad islámica dotó a la cerámica de un poder de representación social y política que no había tenido en tiempos precedentes, en la antigua Roma o en Bizancio. La herencia del mundo clásico reclamaba que las vajillas de representación debían ser de metales preciosos, mientras la cerámica era algo ordinario y de uso común muy generalizado por lo que no conllevaba ningún significado de distinción. El Islam, sin embargo, sí aprovechó y potenció los conocimientos técnicos de la cerámica del mundo romano no carentes de sofisticación que habían sido utilizados para realizar una producción decorativa a molde de carácter masivo, dominar la técnica de los engobes sinterizados que permitían la producción de la terra sigillata o los acabados brillantes llamados lucentes, y difundir ampliamente incluso los vidriados de plo$\mathrm{mo}^{1}$. Para su cocción fue general el uso de hornos verticales de doble cámara y tiro directo $^{2}$, complementados por elementos como los conductos o toberas para conducir

1 J. PÉREZ-ARANTEGUI, I. URUÑUELA y J.R. CASTILLO, "Roman Glazed Ceramics in the Western Mediterranean: Chemical Characterization by Inductively Coupled Plasma Atomic Emission Spectrometry of Ceramic Bodies", Journal of Archaeological Science, 23 (1996), pp. 903-914.

2 J. COLL CONESA, "Hornos romanos en España. Aspectos de morfología y tecnología", D. BERNAL y A. RIBERA (coords.), Cerámicas hispanorromanas. Un estado de la cuestión, Cádiz, 2008, pp. 113-125, y "Pervivencias de los hornos cerámicos clásicos en el mundo hispanomusulmán", D. BERNAL et al. (coords.), Hornos, talleres y focos de producción alfarera en Hispania, Cádiz, 2013, vol. II, pp. 433-451. 
el gas caliente o las cobijas, sistemas de cocción que empleaban la técnica de la radiación calorífica para no afectar a la superficie de las piezas y conseguir superficies de color uniforme. Esas técnicas, junto con las que pervivían en Oriente Medio heredadas de la Persia sasánida, constituyeron la base que permitió el desarrollo de la cerámica islámica. Oliver Watson llama la atención sobre la rápida y extraordinaria difusión de la nueva cerámica impulsada por la naciente sociedad que se extendió junto con el imperio islámico desde Asia Central a al-Andalus en apenas dos siglos ${ }^{3}$. Esta incorporaba como mayores novedades el uso extensivo del recubrimiento vítreo y una nueva iconografía que reflejaba el mundo espiritual y los ideales de la nueva sociedad.

\section{Grupos técnicos básicos de la loza de carácter áulico producida en el periodo medieval en la Península Ibérica}

Basándose fundamentalmente en la cerámica vidriada, Oriente desarrolló un grupo de familias técnicas de valor ornamental difundidas desde los centros de poder, en especial desde la corte califal abasí de Bagdad. Sin duda, esta se constituyó, en el s. IX, como modelo de organización y de protocolo a seguir por todos los centros de poder de la sociedad islámica al interpretar y emular los aspectos de ostentación y lujo de las antiguas cortes persas, bizantinas, indias y chinas. Entre las aportaciones de esa corte, instalada primero en Samarra y posteriormente en Basora, encontramos la creación de un ajuar áulico que contemplaba los múltiples aspectos de la vida cotidiana, desde el mobiliario en madera a la eboraria, las artes del metal, el textil, las alfombras y tapices o las cerámicas, desarrollando también patrones de conducta y etiqueta asociados a su uso. Las cerámicas utilizadas en la corte del califato de Bagdad incluían también las primeras porcelanas y la loza vidriada china que llegaban fruto de los contactos con Extremo Oriente a través de la Ruta de la Seda, consolidados gracias al establecimiento de una importante comunidad islámica en Xian desde el año 651 d.C., cerámicas que claramente sirvieron de modelo para las producciones de valor áulico. Entre ellas, solo las lozas policromas recubiertas de vidriado de plomo, las de vidriado estannífero y las lozas doradas, tuvieron una repercusión significativa en el occidente musulmán gracias a la difusión tanto de su técnica de fabricación como de sus modelos y protocolo de uso, mientras las lozas decoradas con engobe bajo cubierta o la familia de lozas de pastas de frita apenas fueron conocidas en al-Andalus, llegando solo como bienes de importación ocasional.

En anteriores aproximaciones ${ }^{4}$ ya hemos comentado las diversas categorías de los bienes cerámicos en función de su complejidad técnica y uso y las implicaciones que este aspecto conlleva en cuanto a la consideración social más o menos discriminante o integradora de sus productores, desde los humildes materiales de construcción,

\footnotetext{
3 O. WATSON, Ceramics from islamic lands. The Al-Sabah collection, Londres, 2004.

4 J. COLL CONESA, "La producción cerámica medieval. Un balance entre el mundo islámico y el feudal. El caso del área valenciana”, A. GARCÍA PORRAS (coord.), Arqueología de la producción en época medieval, Granada, 2013, pp. 211-257.
} 
pasando por la cerámica del agua, la de fuego y finalmente la vajilla de mesa, entre la que alcanza una gran sofisticación técnica la loza y en especial la dorada. Desde luego, el trabajo del barro se considera por la sociedad islámica una tarea impura, y sus agentes, situados fuera de los grupos agnáticos y vinculados socialmente solo por el oficio, ascendían en consideración dentro de la escala social en función de su pertenencia a grupos que poseían conocimientos más y más especializados y sofisticados. Sin embargo, no cabe pensar que un artesano capaz de ejecutar un determinado nivel pudiera incrementar sus conocimientos para ascender en esta escala de técnicas y conocimientos, ya que, en principio, no le estaba socialmente permitido si no empezaba todo el proceso educativo desde el estado de aprendiz, en iraní llamado sāgerd y en occidente muta 'allim, al de maestro o mu'allìm (ref. Al-Saqati Al-Malaqí, 11471236) ${ }^{5}$. Conocemos los nombres de alfareros andalusíes por elementos de producción en los que aparece su nombre o su autoria 'amal, según hallazgos de Cáceres, Estepona, Tolmo de Minateda o Mallorca ${ }^{6}$, pero en Siria o Persia llegaron a firmar sus trabajos con epigráficos sobre las propias piezas ${ }^{7}$.

En relación con la técnica cerámica potenciada por el Islam, O. Watson llama la atención también sobre los nuevos hornos que se difundieron con la expansión islámica. Mientras la alfarería ordinaria siguió cociéndose en los precedentes hornos verticales de doble cámara con piso de separación formado por una parrilla perforada, la sociedad islámica desarrolló para la cocción de los vidriados un modelo de horno vertical de tiro directo, llamado en árabe shākhüreh y en persa dān o $d a h s t^{8}$, de una sola cámara, en el que los elementos a cocer se colocaban sobre estantes formados por barras (arsh o dhirā') que se incrustan en el muro ${ }^{9}$, que medían un arash de longitud (distancia que separa el codo del nacimiento de los dedos), que según el tratado del s. XIV de Abu'l-Qasim se cocían durante doce horas ${ }^{10}$. Conocidos como

5 R. ARIÉ, España Musulmana (siglos VIII-XV), M. TUÑÓN DE LARA, Historia de España, vol. III, 1984, p. 268; R. IRWIN, Islamic Art in Context, Londres, 1997, p. 134.

6 J.M. TOMASSETTI et al. "Viviendas de época nazarí en el nuevo arrabal de Istibuna (Estepona, Málaga)", Pre-actas del Congreso Internacional "El espacio doméstico en la península ibérica medieval. Sociedad, familia, arquitectura, ajuar”, Granada, 2013; S. GUTIÉRREZ LLORET, “Cerámica y escritura: dos ejemplos de arabización temprana. Graffiti sobre cerámica del Tolmo de Minateda (Hellín, Albacete)", S. GÓMEZ MARTÍNEZ (coord.), Al-Andalus, espaço de mudança, Balanço de 25 anos de historia e arqueologia medievais, Homenagem a J. Zozaya Stabel-Hansen, Mértola, 2006, pp. 52-60; y J. COLL CONESA et al., "La alfarería musulmana de época taifa del carrer de Botons de Palma de Mallorca", Atti del IX Congresso Internazionale sulla Ceramica Medievale nel Mediterraneo, Borgo S. Lorenzo, 2012, pp. 236-245.

7 E. GRUBE, "The Art of Islamic Pottery", The Metropolitan Museum of Art Bulletin, 23 (1965), pp. 209228; O. WATSON, op cit, 2004, p. 354. También las lozas doradas abadíes de Al Mu'tadīd (vid. nota 68) portan el nombre del comitente y mencionan que fueron realizadas por esclavos, lo que denota un claro control de esta producción en la taifa de Sevilla.

8 La información nos ha llegado gracias a un tratado persa. Véase por ejemplo J.W. ALLAN, “Abu'l Qāsim's Treatise on Ceramics", Iran, 11 (1973), p. 114.

9 O. WATSON, op cit, 2004, p. 35.

10 Explicado por otra versión del texto de Abu'l Qasim. Véase Z. ROUHFAR y J. NEYESTANI, “Technique de la préparation de l'émail à reflet métallique d'aprés le 'Ara'es-Ad-Javaher nafa'es-al-ata'eb d'Abolqassem 'Abdollah Kachani”, Iran, 46 (2008), pp. 179-187; Y. PORTER, Le prince, l'artiste et l'alchimiste. La céramique dans le monde iranien $X^{\grave{e}}$-XVIII ${ }^{\grave{e}}$ siècle, París, 2011. 
"hornos de barras"11, estas estructuras podían elevar la temperatura de combustión más allá de los límites de los modelos previos, ya que algunos de ellos incorporaron incluso chimeneas internas con salida de humos desde la parte inferior de los muros para provocar un tiro de llama invertida, técnica que ha sido documentada en hornos andalusíes de Zaragoza y Córdoba ${ }^{12}$. En esos hornos, la combustión se realizaba en un largo corredor excavado, que actuaba como hogar, que desembocaba en la parte inferior de la cámara de cocción o laboratorio. Esta disponía de un espacio libre inferior a la altura del hogar, a veces con un banco o escalón perimetral, y a partir de una cierta altura, señalada en su caso por la parte superior de ese banco, presentaba los pisos horizontales construidos con barras de arcilla cocida incrustadas en el muro de barro, bien directamente, bien mediante la ayuda de unos cilindros o cazoletas de arcilla empotradas en las paredes formando hileras horizontales. Si el horno era de tiro directo, los gases de combustión se evacuaban por la bóveda que remataba la cámara. Si era de llama invertida, el horno debía disponer de una bóveda cerrada, con lo cual los gases calientes ascendían hasta ella para luego descender hacia las salidas de la chimenea ubicadas en la parte inferior de los muros. Con este sistema se aprovecha mucho más el poder calorífico de los gases ya que la llama incide hasta tres veces el espacio donde se disponen las piezas a cocer, dos veces por la cámara interna y una tercera por los conductos que la conducen hasta la chimenea que calienta además los propios muros del horno. La temperatura alcanzada por este tipo de horno superaba sin duda la del horno romano y seguramente reducía el consumo de combustible. La fabricación de loza vidriada, y en especial de la decorada con esmalte estannífero, debió precisar de esta innovación al necesitar algo más de temperatura que la cocción del bizcocho cerámico.

\section{Las producciones cerámicas medievales y su tecnología}

En este apartado describiremos los principales grupos técnicos que tuvieron un carácter áulico en la sociedad andalusí y en los reinos cristianos bajomedievales. Ya indicábamos en la introducción que solo tres alcanzaron esta consideración: la loza vidriada de plomo, la loza estannífera y la loza dorada. Analizaremos la primera de ellas ya que es la base técnica de las demás aunque no fue utilizada expresamente como un soporte de valor áulico. Sin embargo, en al-Andalus la cuestión es algo más compleja ya que, a pesar de que realmente solo la loza estannífera y la dorada tuvieron series áulicas per se, un gran número de series de técnicas variadas gozaron de características que las situaron en un plano de representación social elevado, como por ejemplo la loza de cuerda seca, la esgrafiada o la azulejería. Por otra parte, si observamos la atomización de núcleos de poder que surgieron en al-Andalus, especialmente en las etapas de reinos de taifas, pero también como causa de su sistema

11 J. THIRIOT, "Bibliographie du four de potier à barres d'enfournement", IV Congreso de Arqueología Medieval Española, Alicante, 1994, vol. III, pp. 787-798.

12 J. COLL CONESA y A. GARCÍA PORRAS, "Tipologia, cronologia e produzione dei forni per ceramica in Al-Andalus", Atti. XLII Convegno internazionale della ceramica, Albisola, 2010, pp. 25-44. 
social de representación político-administrativo que se extendía a todas las ciudades y núcleos de población importantes, podemos vislumbrar que el panorama se complica enormemente.

\section{La loza vidriada en al-Andalus}

Las cubiertas vítreas se suelen denominar barniz en la bibliografía genérica. Dada la confusión que puede generar este término, usado por ejemplo para describir los engobes sinterizados de la Antigüedad - denominación más adecuada- (barniz negro de la cerámica griega ática o de la cerámica campaniense, o barniz rojo de la terra sigillata), así como en los tratamientos orgánicos a base de almidones, ceras, sebos, colas, resinas y alquitranes, consideramos oportuno el uso del término vidriado o vedrío cuando el recubrimiento no es de naturaleza orgánica ni sea un engobe que haya alcanzado un alto grado de fusión superficial. La cerámica vidriada aparece mencionada en la documentación como tarschisch (Ibn Hawqal, 950), hantam (Ibn 'Abdun, s. XII) o, más genérico, muzajaj.

Un vidriado tradicional, como los usados en época medieval, se compone de óxidos fundentes u óxidos básicos $\left(\mathrm{Na}_{2} \mathrm{O}, \mathrm{K}_{2} \mathrm{O}, \mathrm{CaO}, \mathrm{PbO}\right)$, de vitrificantes u óxidos ácidos $\left(\mathrm{SiO}_{2}, \mathrm{~B}_{2} \mathrm{O}_{3}\right)$ y de estabilizantes u óxidos neutros $\left(\mathrm{Al}_{2} \mathrm{O}_{3}\right)$. Estos componentes deben estar ajustados a las características del cuerpo cerámico y a la temperatura y condiciones de cocción para madurar adecuadamente. Por ello varían en las proporciones de sus componentes en función de esas condiciones ${ }^{13}$.

El vidriado habitual durante la antigüedad romana se basaba en dos grupos básicos: por un lado el alcalino compuesto por sílice y alúmina, originado en Oriente Medio, que utilizaba como fundentes sales sódicas, potásicas y de magnesio; por otro, el vidriado de silicato de plomo compuesto de plomo, sílice y alúmina ${ }^{14}$, base de la tecnología de los vidriados cerámicos que se usaron en la Península Ibérica durante el medioevo.

La técnica cerámica usada en Oriente Medio nos es conocida por fuentes directas, siendo la más completa y general el tratado escrito por Abu'l-Qasim el Kasaní en 1301 del que hemos manejado dos versiones ${ }^{15}$. Este autor, perteneciente a la tribu Abu Tahir de Kashan, divide su tratado en tres partes: en la primera describe los materiales y equipos necesarios, en la segunda expone cómo disolver las sustancias y en la tercera cómo combinarlas. En relación con el vidriado de plomo, el procedimiento de fabricación se explica indicando que se mezclan 105 partes de un componente que se llama shukar-i sang (cuarzo) y 100 partes de shakhār o qali (sodio), obtenido de plantas, que deben ser molidos y filtrados con un paño de seda, formando pequeños terrones que se introducen en un horno llamado harīz. Tras cocer durante seis horas a fuego lento mientras se remueve con una cuchara larga, desde la mañana a la noche, queda como vidrio fundido. Tras ocho horas se extrae la materia fundida y se vierte

\footnotetext{
13 F.H. NORTON, Cerámica para el artista alfarero, México, 1978, pp. 432-452.

14 K. GREENE, "Late Hellenistic and Early Roman Invention and Innovation: The Case of Lead-Glazed Pottery”, American Journal of Archaeology, 111, 4 (Oct., 2007), pp. 653-671.

15 Las de J. ALLAN y Z. ROUHFAR citadas en las notas 6 y 8.
} 
en un recipiente con agua situado frente a la puerta del horno, donde se enfría con un gran estruendo formando un cristal llamado jawar. Para usarlo hay que molerlo hasta reducirlo a polvo y se afirma, en técnica moderna, que este enfriamiento rápido produce un estallido que forma cristales en estrella más fáciles de moler ${ }^{16}$. Esta frita de sílice y fundente alcalino se debe combinar luego con plomo, cuyo mineral molido, tamizado y cocido cuarenta y ocho horas dentro de una olla (crisol), permite conseguir un óxido de plomo que llamaban shangarf. En el texto de Abu'l-Qasim se indica que este vidrio también es la base para las pastas de frita. En el apartado siguiente comentamos cómo se realiza el vidriado de estaño plomo según este texto, pero es interesante aclarar las técnicas tradicionales usadas para la obtención del vidriado de plomo ya que son la base de desarrollos ulteriores de larga trayectoria.

Siendo los hornos de frita, usados en estos procesos, un elemento fundamental, cabe recordar que Jacques Thiriot ha recopilado los testimonios arqueológicos y varios modelos históricos para la fabricación de vidriados cerámicos ${ }^{17}$. Comenta que en Nabeul (Túnez) el alfarero compra restos de plomo y los funde en un horno llamado mah'raq, que consta de dos partes conectadas por un conducto, un hogar y una cámara o crisol en la que se deposita el material ya fundido. El plomo se calienta y funde mientras se remueve con atizaderos, retirándose la capa superior que se va formando que deviene compuesta únicamente por óxido de plomo. Luego debe mezclarse con cuarzo y arcilla para conseguir el vidrio.

Manuel González Martí18 comenta cómo se realizaba la preparación del vidriado de plomo en los talleres de Manises en la primera mitad del s. XX. Para la oxidación del plomo se usaba un horno de reverbero llamado armele, término derivado del árabe referido a la arena ${ }^{19}$. Afirma que removiendo la galena con una paletilla llamada dragó durante siete horas, a una temperatura de $650{ }^{\circ} \mathrm{C}$, el mineral se convertía en una arena de óxido de plomo llamada acercó. Esta se mezclaba con arena silícea y sal común y se colocaba en tarros o crisoles o en huecos al efecto, situados en la parte posterior del hogar del horno (sagen), para que formara un vidrio. El resultado, llamado alcofoll o alcohol alfarero, se molía y servía ya para vidriar realizando una suspensión acuosa. Para la correcta aplicación sobre las piezas era necesario remover la mezcla para mantener las partículas en suspensión de forma homogénea.

En relación con los vidriados de plomo usados en la Península Ibérica durante la época medieval, se ha observado que su composición varía ligeramente según sea su color dominante amarillo, melado, castaño o verde de reducción por monococción, conteniendo este último menos proporción de fundentes plúmbicos y estabilizantes y mayor porcentaje de $\mathrm{CaO}$ dado que deben cocer al unísono con el cuerpo cerámico. La formación del color verde en vidriados a los que no se ha añadido Cu para provocar ese color, se debe a la reducción de la pasta al estar cubierta por el vidrio en fusión

16 F.H. NORTON, op. cit., 1978, p. 460.

17 J. THIRIOT, "Les fours pour la préparation des glaçures Dans le monde méditerranéen", La céramique Médiévale en Méditerranée. Actes du 6e Congrès de l'AIECM, Aix-en-Provence, 1997, pp. 513-522.

18 M. GONZÁLEZ MARTí, Cerámica del Levante español. Siglos medievales, t. I, Loza, Barcelona, 1944, p. 25.

19 Ya he comentado en otras ocasiones que Eguilaz (1886) indica que los hornos musulmanes eran llamados Almala y Almila en Granada. 
que impide la penetración de oxígeno de la combustión, fenómeno que paralelamente produce la formación de óxido ferroso que migra hacia el vidriado ${ }^{20}$. Cabe decir que la monococción de los vidriados de plomo se documenta en al-Andalus en cronologías avanzadas, frente a la bicocción predominante de los periodos califal y taifa.

Existe una cierta incertidumbre acerca de si en las primeras ciudades andalusíes omeyas se fabricó cerámica vidriada. Por otra parte, parece que esta perduró desde la Antigüedad y siguió siendo necesaria en las últimas etapas del reino visigodo y que, bien para la industria del vidrio mismo, bien para su aplicación como recubrimiento en cerámica de cocina, siguió en producción hasta la conquista islámica, según se ha constatado en Tarragona, Barcelona, Valencia, Albacete y Mérida ${ }^{21}$. La presencia de cerámica vidriada en el s. VIII en contextos como el Horizonte I del Tolmo de Minateda, en el territorio de Tudmir, se considera evidencia de la existencia de producciones vidriadas residuales de época visigoda ${ }^{22}$. Durante el s. VIII se constata raramente el uso de cerámica vidriada en al-Andalus aún en ciudades tan importantes como Córdoba, donde los descubrimientos arqueológicos realizados en el barrio de Saqunda, destruido en el 818, manifiestan que era desconocida en ese lugar ${ }^{23}$. El vidriado islámico empieza a documentarse en el s. IX en Bayyana y Almería ${ }^{24}$, mientras la aparición de trébedes en el Tolmo de Minateda, abandonado en los inicios del s. X, indicaría que allí también se fabricó ${ }^{25}$. De hecho, los primeros vidriados monocromos decorados bajo cubierta son uno de los elementos destacados del reconocimiento general de los contextos arqueológicos del s. IX en este último yacimiento pertenecientes a la fase 3 del horizonte II $^{26}$.

La cerámica vidriada de cierta calidad de época omeya se presenta en tres grupos decorativos. Existen ejemplares con decoración monocroma, únicamente vidriada. Sin embargo, las más ricas se completan con elementos trazados en verde de óxido de cobre o negro de óxido de manganeso permitiendo añadir elementos de valor simbó-

20 J. MOLERA, M. VENDRELL-SAZ y M. GARCÍA-VALLÉS, “Technology and colour developement of hispano-moresque lead glaze pottery", Archeometry, 39, I (1997), pp. 23-39; J. MOLERA et al., op. cit. (1999), p. 23; M. PICON, J. THIRIOT y L. VALLAURI "Techniques, évolutions et mutations", Le Vert \& le Brun. De Kairouan à Avignon. Céramiques du $X^{e}$ au XV siècle, Marsella, 1997, pp. 41-50.

21 M. ALBA CALZADO y S. GUTIÉRREZ LLORET, "Las producciones de transición al Mundo Islámico: el problema de la cerámica paleoandalusí (siglos VIII y IX)”, D. BERNAL y A. RIBERA (coords.), Cerámicas hispanorromanas, un estado de la cuestión, Cádiz, 2008, p. 589.

22 S. GUTIÉRREZ, B. GAMO y V. AMORÓS, "Los contextos cerámicos altomedievales del Tolmo de Minateda y la cerámica altomedieval en el sudeste de la Península Ibérica”, L. CABALLERO, P. MATEOS y M. RETUERCE (eds.), Cerámicas tardorromanas y altomedievales en la Península Ibérica. Ruptura y continuidad, Mérida, 2003, pp. 119-168.

23 M.T. CASAL, E. CASTRO, R. LÓPEZ y E. SALINAS, "La cerámica emiral del arrabal de Šaqunda (Qurtuba) (mediados del siglo VIII - 818 d.C.)", J. ZOZAYA et al. (eds.), Actas del VIII Congreso Internacional de Cerámica Medieval en el Mediterráneo, Ciudad Real, 2009, t. II, pp. 1027-1030.

24 M. ALBA CALZADO y S. GUTIÉRREZ LLORET, op. cit., 2008, p. 589

25 B. GAMO PARRAS y S. GUTIÉRREZ LLORET, "Los hornos de El Tolmo de Minateda (Hellín, Albacete). Estructura y producción, J. ZOZAYA et al. (eds.), op. cit., 2009, t. II, pp. 839-848.

26 S. GUTIÉRREZ, "La islamización de Tudmīr: balance y perspectivas", P. SÉNAC (ed.), Villes et campagnes de Tarraconaise et d'al-Andalus (VIe-XIe siècles): la transition, Toulouse, 2007, p. 306; V. AMORÓS, Contextos cerámicos del siglo VIII en el Tolmo de Minateda, Albacete, 2011, p. 119. 
lico a través de la decoración, componente esencial en la cerámica áulica islámica ${ }^{27}$. Por tanto existe una producción bicroma, en general con trazos negros o verdes sobre vidriado de plomo (grupo B-2-a de Retuerce y Zozaya) o policroma, decorada en verde y negro con vidriado de plomo (grupo B-2-c). A pesar de ello, siendo patente que sus temas decorativos se relacionan simbólicamente con los ideales religiosos, dudosamente podemos considerar que en Madīnat al-Zahrā' ese grupo cerámico poseyera valor áulico dado que su iconografía era pobre, en relación con la loza estannífera, y se centraba en cenefas de borde con semicírculos, cresterías y flores de loto, a veces simbolizando el Paraíso. Estas producciones se encuentran bastante extendidas en todas las ciudades y asentamientos pertenecientes a los años finales del s. X e inicios del s. XI.

Para su cocción se requiere generar una fuente calorífica de radiación, es decir, que se dificulte que los gases puedan incidir directamente sobre la pieza, al tiempo que son preferibles los enfriamientos largos y la temperatura debe alcanzar los 800 y 950 ${ }^{\circ} \mathrm{C}$ para una buena maduración ${ }^{28}$, siempre en función de la composición del vedrío. Aunque hoy es general el uso de cobijas o gacetas para ello, no se han documentado en yacimientos medievales, lo que indica que la radiación calorífica se debía obtener organizando cuidadosamente la carga del horno y creando barreras de piezas bizcochadas debajo y a los lados de las cerámicas a vidriar. La arqueometría nos indica que el grosor de los vidriados de plomo medievales se encuentra entre $80 \mu \mathrm{m}$ y $140 \mu \mathrm{m}$ y que la interfase de reacción cuerpo-vidriado generada durante la cocción es también indicativa de si fueron cocidos en monococción (grosor de 30-40 micras) o en bicocción (grosor de 5-10 micras).

A pesar de su relativa simpleza, la tecnología utilizada en esta producción nos habla de que los alfareros capaces de ejecutarla poseían conocimientos especializados que requerían de una larga formación. La diferencia con el grupo siguiente estriba en la ausencia del uso de un opacificante y por tanto muestra una aparente inferior calidad final. Sin embargo, tanto el procesado del barro, el torneado de las piezas que exigía muchos años de experiencia, como la propia complejidad de la producción del vidriado, manifiestan ese carácter especial. Unos rasgos que solo se ven minimizados por el hecho de que su decoración no fue acabada por un artista formado en la disciplina iconográfica al representar elementos estilizados de repertorio, que podían realizar los propios alfareros.

\section{Opacificación por estaño}

No todas las lozas que poseen una superficie vidriada blanca poseen estaño. En el Medio Oriente se desarrollaron varias técnicas para conseguir una superficie blanca y

27 Para una visión general de las producciones véase B. MARTÍNEZCAVIRÓ, Cerámica hispanomusulmana andalusí y mudéjar, Madrid, 1991. Los motivos decorativos han sido sistematizados y estudiados por M. RETUERCE y J. ZOZAYA, "Variantes geográficas de la cerámica Omeya andalusí: los temas decorativos", La ceramica medievale nel Mediterraneo occidentale. Atti del III Congresso Internazionale, Florencia, 1986, pp. 69-128. Véase también J. ZOZAYA, "Símbolos", C. TORRES y S. GÓMEZ MARTíNEZ (eds.), Os signos do quotidiano. Gestos, marcas e símbolos no Al-ândalus, Mértola, 2011, pp. 11-21.

28 J. MOLERA et al., op. cit. (1999), p. 22. 
una de ellas es la llamada loza estannífera, es decir, la recubierta por un vidrio de plomo, estaño y sílice, también llamado esmalte de estaño. A diferencia de los vidriados de plomo, traslúcidos por naturaleza, en estas se añade al vidrio el óxido de estaño o casiterita formando partículas cristalinas que limitan su traslucidez, lo opacifican y le confieren el color blanco. Ese fondo proporcionaba a estas cerámicas una superficie de inmejorable calidad para que destacara la decoración sobre ella. Además, los colores blanco, verde y negro, usados en al-Andalus, obtenidos con óxidos de estaño, cobre y manganeso, tenían también un significado simbólico que ha sido comentado por M. Barceló y J. Zozaya ${ }^{29}$.

Un primer problema en relación con el estaño es la procedencia del mineral. Abul'Qasim comenta que en Persia se obtiene del norte del Khurasán, Astrabad, Sistan, Lorestán, Kermán, el litoral del Mar Caspio, Tabiz o Isfahan. En el occidente mediterráneo las fuentes de aprovisionamiento eran más reducidas. Las fuentes árabes indican que en al-Andalus el estaño se extraía de Ocsonoba, según comenta al-Bakrī, pero también era conocido el "plomo blanco", según lo llamaba San Isidoro en sus Etimologías, procedente de Gallaecia y Lusitania ${ }^{30}$. En el altomedievo, el estaño de Inglaterra era exportado a Europa Central y ya en el s. XII se distribuía desde ciudades mediterráneas como Marsella o Narbona. En el s. XIV los mercaderes italianos controlaban prácticamente su exportación ${ }^{31}$. Si raras son las noticias sobre su comercio en al-Andalus, es sintomático que los encargos de loza estannífera de Manises de la primera mitad del s. XIV indicaran que el comitente debía aportarlo junto con el plomo ${ }^{32}$, situación que parece normalizarse con un comercio más fluido desde la segunda mitad de dicho siglo.

La arqueometría ha proporcionado una valiosa información sobre la naturaleza de las cubiertas blancas usadas en al-Andalus. Durante mucho tiempo se afirmó que estas se realizaron con un engobe bajo cubierta. Se suponía que sobre el barro se aplicaba una capa de arcilla blanca que posteriormente se cubría con vidriado de plomo y se decoraba ${ }^{33}$. Esta afirmación se debía al estado de completa alteración de los vidria-

29 M. BARCELÓ, “Al-Mulk, el verde y el blanco: la vajilla califal omeya de Madīnat al-Zahrāa”, A. MALPICA (ed.), La cerámica altomedieval en el sur de al-Andalus. Primer Encuentro de Arqueología y Patrimonio, Granada, 1990, pp. 291-299; J. ZOZAYA, op. cit., 2011.

30 O. PUCHE, "La minería visigótica y musulmana en la Península Ibérica", Bocamina. Patrimonio minero de la región de Murcia, Murcia, 2005, pp. 67-92; A. CANTO y P. CRESSIER (coords.), Minas y metalurgia en Al-Andalus y el Magreb occidental: explotación y poblamiento, Madrid, 2008.

31 M. CAROSCIO, "La transizione fra Medioevo e Rinascimento e l'impiego del blu nelle smaltate basso medievale italiane. Materie prime e luoghi di approvviggionamento: fonti scritte e analise archeometriche a confronto", R. LAVAGNA (ed.), Atti. XL Convegno Internazionale della Ceramica, Borgo S. Lorenzo, 2007, pp. 193-204, y "Si cava in Inghilterra, et anche in certi luochi de la Fiandra: tin trade and technical changes in pottery making", S. GELICHI (ed.), Atti del IX Congresso internazionale sulla ceramica medievale nel Mediterraneo, Borgo S. Lorenzo, 2012, pp. 64-67; A. MCSWEENEY, "The Tin Trade and Medieval Ceramics: Tracing the Sources of Tin and its influence on Mediterranean Ceramics Production”, Al-Masāq, 23, 3 (2011), pp. 155-169.

32 Ya fue observado por G.J. de Osma y Pedro López Elum, según recoge J. COLL CONESA, La cerámica valenciana. Apuntes para una síntesis, Valencia, 2009, p. 57.

33 M.J. RUBIO VISIERS, "La técnica de la engalba blanca bajo cubierta en la submeseta sur", II Congreso de Arqueología Medieval Española, Madrid, 1987, p. 12. También J. MOLERA et al., op. cit. (1999), p. 26, comentan que en el alfar de San Nicolás de Murcia los vidriados parecían engobes por su alteración. 
dos que muchas piezas presentaban, mostrando una superficie blanca y pulverulenta. Este aspecto se debía en realidad a un problema de desvitrificación provocado por la falta de estabilidad del esmalte estannífero ya que numerosos análisis realizados han demostrado que sin duda poseen estaño ${ }^{34}$, lo que indica la pronta adaptación en el califato cordobés de una técnica cerámica de origen oriental. Allí, cabe buscar el origen de las lozas cubiertas con un vidrio blanco en la copia de las cerámicas de cuerpo blanco llegadas con la Ruta de la Seda desde China, especialmente del gres blanco porcelánico desarrollado bajo la dinastía Tang. Las formas de los cuencos y jarras abásidas copiaban exactamente a las protoporcelanas chinas, pero mientras las piezas originales presentan blancas tanto pastas como cubiertas, las imitaciones iraquíes poseen el cuerpo en arcilla rosada u ocre con un recubrimiento de vidriado blanco. El vidrio blanco no solo se opacificaba con estaño, ya que el cuarzo solo es también un buen opacificante y así se usó en determinados centros de producción orientales, según describe el propio Abul'Qasim ${ }^{35}$ aunque esta tecnología no se desarrolló en al-Andalus. A las ciudades abásidas llegaron esas primeras porcelanas, pero también alcanzaron el extremo Occidente, ya que disponemos de hallazgos de esas cerámicas Tang tanto en Almería como en Cullera ${ }^{36}$. Si bien en Irak encontramos estas cerámicas en el s. IX en el foco Samarra / Basra, se atribuye al segundo la especialización en la decoración de loza estannífera blanca decorada con azul de cobalto y con la técnica reflejo metálico que analizaremos más adelante. La difusión de las lozas estanníferas fue muy rápida y ya en el s. IX se constatan focos en Nishapur, en Raqqa y al-Mina (Siria), en Fustat (Egipto), en Sirjan, Siraf y Rayy (Irán) y hasta en Samarcanda. Incluso se fabricó en Túnez bajo los aglabides llegando en el s. X a al-Andalus, tanto a Madinat Ilbira como a Madīnat al-Zahrā'.

El desarrollo tecnológico que permitió la creación del vidrio blanco de plomo, estaño y cuarzo en la Antigüedad, base de la loza estannífera, se encuentra también en Oriente Medio. Los primeros opacificantes para vidrios, compuestos por óxidos o sales metálicas que alteran el color del vidrio y permiten que aparezca de color blanco o amarillo, consistían en antimoniato de plomo amarillo y antimoniato de calcio blanco, y fueron usados en Egipto desde mediados del segundo milenio a.C. Sin embargo, ya en el s. II a.C. se empezaron a usar los opacificantes de estaño (estannato de plomo amarillo y óxido de estaño blanco) junto con los de antimonio en la fabricación de cuentas de pasta de vidrio, práctica que se extendió desde el s. IV d.C. en la musivaria producida en los actuales territorios de Egipto, España, Grecia,

34 G. BERTI y T. MANNONI, "Ceramiche medievali del Mediterraneo Occidentale: Considerazioni su alcune caratteristiche tecniche", A Cerâmica Medieval no Mediterrâneo Ocidental, 1991, pp. 163-173; F. GONZÁLEZ GARCÍA et al., "Estudio arqueométrico de algunas cerámicas medievales de Madinat Al-Zahra (Córdoba)", Boletín de la Sociedad Española de Cerámica y Vidrio, 31, 6 (1992), pp. 491-498; y J. COLL CONESA et al., "Caracterización química de cubiertas blancas opacas musulmanas de la Valencia medieval (ss. X-XI)", Cesaraugusta, 73 (1999), pp. 49-58.

35 J. ALLAN, op cit, 1973, ap. 18.

36 J. ZOZAYA, "Chinese porcelain in Caliphal Spain", Pottery and metalwork in T'ang China. Their chronology and external relations, Londres, 1971, pp. 54-57, y también "Importaciones casuales en AlAndalus: las vías de comercio”, IV Congreso de Arqueología Medieval Española, Alicante, 1993, t. I, pp. 119-138. Sobre nuevos hallazgos de importaciones, J. COLL CONESA, "Cerámicas de importación: series y cronología”, J. COLL (dir.), Manual de Cerámica Medieval y Moderna, Madrid, 2011a, pp. 271-304. 
Israel, Italia y regiones de Inglaterra, Irlanda, Alemania y Dinamarca ${ }^{37}$. El primer vidriado cerámico opacificado con estaño, sin embargo, fue desarrollado en el s. IX en el califato abásida en Irak y pronto se extendió, como hemos dicho, hasta los confines mediterráneos de al-Andalus ${ }^{38}$.

La técnica de la opacificación es descrita ya por Abu'l-Qasim. El estaño es llamado arziz y debe calcinarse sucesivas veces a fuego lento con azufre, agua y sal en un crisol tapado con barro, refinando y moliendo tras cada cocción. Se obtiene un sulfuro de estaño que después de ser calcinado se transforma en dióxido de estaño ${ }^{39}$. En el horno de reverbero, el plomo se calienta y se le añade posteriormente el estaño, cerrando el horno con barro durante media jornada para obtener el sorandj, base del esmalte de estaño (sefidab). Se recalienta entonces durante veinticuatro horas y se le añade, a partes iguales, la piedra blanca llamada qamsari y fundente alcalino o chakkar, obtenido de la ceniza procedente de los tallos de una planta llamada ashnan (Salsola soda). Se mezclan $3 \mathrm{kgr}$ de sorandj por cada $9 \mathrm{kgr}$ de la mezcla alcalina y se recalienta hasta obtener una substancia blanca.

González Martí comenta que en Manises se hacía tradicionalmente mezclando 60 partes de plomo con diez de arena y una y media o dos de estaño ( $3 \% \mathrm{Sn})$. Sin embargo, esta parece una proporción moderna como veremos posteriormente. Según González Martí, para conseguir una buena transparencia convenía añadir el estaño mientras se hacía la oxidación del plomo en el armele. Cuando este llegaba al estado de óxido se añadía el estaño y continuaba removiéndose para añadirse luego la arena. Luego se extraía del horno para ser molido y tras ello se cocía en el sagen, como el vidriado de plomo.

Según Abu'l-Qasim, para aplicar el vidrio sobre la pieza se prepara una mezcla de vidriado molido emulsionado con katira (goma de tragacanto). Esta técnica permite pintar posteriormente sobre la superficie de las piezas sin cocer, sin alterar el vidriado aún crudo. En ocasiones no es necesaria ya que la decoración se puede realizar bajo el vidriado, como más adelante explicaremos. En Manises se distingue entre vernís (vidriado), cuando se da a piezas no decoradas, y coberta (cubierta), cuando se añade en otras que han sido pintadas antes de recibir el baño vítreo ${ }^{40}$.

En los primeros tiempos del Islam andalusí no se desarrolló un aparato cortesano. R. Holod ${ }^{41}$ manifiesta que el refinamiento y los aspectos suntuarios se alcanzaron en la corte omeya del periodo emiral bajo 'Abd al-Rahmān II tras la llegada de Ziryāb, liberto del califa abasí al-Mahdī, al traer la etiqueta y la costumbres de su corte con

37 M. TITE, T. PRADELL y A. SHORTLAND, "Discovery, production and use of tin-based opacifiers in glasses, enamels and glazes from the Late Iron Age onwards: a reassessment", Archaeometry, 50, 1 (2008), pp. 67-84.

38 J. COLL y I. SCHÜTZ, "Die fayence und ihre vorläufer in 'Al Andalus"”, Keramos, 157 (1997), pp. 55-64; J. COLL et al., op. cit. (1999), pp. 49-58; J. MOLERA et al., op. cit. (1999); J. MOLERA et al., "Chemical and Textural Characterization of Tin Glazes in Islamic Ceramics from Eastern Spain", Journal of Archaeological Science, 28 (2001), pp. 331-340.

39 Z. ROUHFAR y J. NEYESTANI, op. cit. (2008).

40 V. FERRÍS y J. M. CATALÀ, La ceràmica de Manises: el seus vocables i locucions, Valencia, 1987, p. 109 .

41 R. HOLOD, “Artes suntuarias del período califal”, Al-Andalus. Las artes islámicas en España, Madrid, 1992, p. 42. 
la música, aspectos del vestir, la educación o la higiene. Sin embargo todo ello llegó a su cénit bajo el Califato de Córdoba, con su ostentación del lujo por la emulación del poder califal oriental que se había dado en las míticas capitales abasíes de Bagdad y Samarra y de la emergente ciudad fatimí de El Cairo. 'Ab al-Rahmān III conquistó Fez y Sijilmassa y con ello controló la fundamental ruta del Oro hacia Khumbi Saleh, capital del reino Sonniké en el Sahel, consolidando el aprovisionamiento de productos codiciados y costosos como el marfil y el oro y con ello el poder califal. Las acciones del primer califa omeya para transmitir y representar el máximo poder califal sobre sus súbditos en el plano religioso y político se plasmaron en la construcción de la nueva ciudad de Madīnat al-Zahrā’, evocadora de las abasíes de Yawsaq o de Balkuwara, y en el traslado a ella de su corte, cancillería, ejército, ceca y los talleres artesanos de tejido (Dār al-tirāz) o de otras artes (Dār al-Sināa), generando un verdadero foco de arte áulico ${ }^{42}$. Se extendió la tradición de afianzar las alianzas con costosos regalos o dádivas, de carácter clientelar o diplomático, que incluían ricos recipientes de madera, marfil o cerámica, contenían perfumes o materias como el ámbar, el almizcle o el alcanfor, y también se extendió el artesanado que permitía que todos los centros urbanos en los que se concentraba el poder se convirtieran, a pequeña escala y proporcionalmente con su poder de representación política, en centros reemisores de objetos portadores de estos mensajes de vinculación social y política y de relevancia y reflejo del poder. En determinadas artes, los artesanos llegaban a firmar los objetos con inscripciones tan destacadas como las de quienes efectuaban o recibían la dádiva, lo que manifiesta la elevada consideración social también de aquellos, como ocurre en la arqueta de Gerona obra de Badr y Tarīf para Hisam II ${ }^{43}$. Todo ello corre paralelo en al-Andalus a la constatación de la primera fabricación de loza opacificada con estaño, a mediados del s. $\mathrm{X}^{44}$, en los primeros centros que ya producían loza vidriada de plomo. Madīnat al-Zahrā', fundada entre 936-945, ofrece las primeros contextos arqueológicos con lozas estanníferas, aunque más segura es la fecha que nos indica la construcción de la macsura de la catedral de Córdoba bajo al-Hakam II (966), en donde vemos impostas cerámicas decoradas con esta técnica. Carlos Cano ${ }^{45}$ llega a proponer que la producción de la loza estannífera califal estuvo fuertemente vinculada a los Dār al-Sināa palaciegos y que sus decoraciones no están exentas de cierto carácter oficial por su relación con el programa ornamental de la propia arquitectura de Madīnat al-Zahrā'.

Cabe pensar que la representación del poder califal pronto difundió una estructura social que reflejó en sus coras y centros administrativos, configurando unas nuevas ciudades capaces de emular la corte inspiradora y de impulsar el papel económico del centro urbano. Hasta qué punto ello facilitó la extensión de la fabricación de técnicas cerámicas sofisticadas impulsadas desde el centro áulico nos es desconocido, pero sí

42 A. VALLEJO TRIANO, "Madīnat al-Zahrā’: el triunfo del estado islámico", Al-Andalus. Las artes islámicas en España, Madrid, 1992, 27-39.

43 R. HOLOD, op cit., 1992, p. 45.

44 M. ALBA CALZADO y S. GUTIÉRREZ LLORET, op. cit, 2008, p. 589; J. ESCUDERO, y M.D. BAENA, "Notas sobre Al-Andalus y su cultura material: de los Omeyas a los Almohades", $A W R A Q, 7$ (2013), pp. 105-120.

45 C. CANO PIEDRA, La cerámica verde-manganeso de Madīnat al-Zahrā, Granada, 1996. 


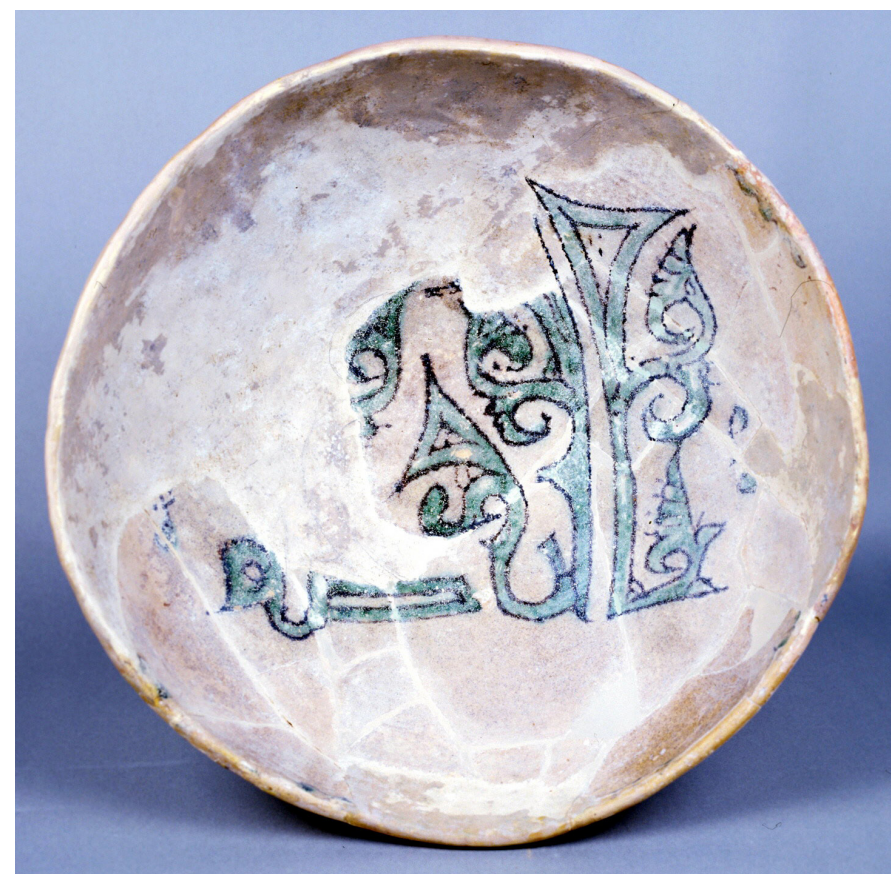

Fig. 1. Cuenco con vidriado estannífero hallado en Benetússer con inscripción Baraka, inicios del s. XI. Depósito del Ayuntamiento de Benetússer en el Museo Nacional de Cerámica.

sabemos que ello ocurrió, ya que nos encontramos con una rápida difusión de lozas estanníferas de marcado carácter regional que además comparten la iconografía fomentada desde el poder califal. Sí se observan morfologías, como las fuentes de base plana y perfil cóncavo, que parecen reclamar una inspiración en la orfebrería. Sin embargo, por razones meramente técnicas, las lozas estanníferas que se producirán en los innumerables alfares de al-Andalus reproducirán masivamente, para el servicio de mesa, modelos de grandes cuencos de servicio colectivo con pie anular externo y cuerpos de desarrollo semiesférico, cónico o quebrado, así como cantarillas o jarras para beber, cántaros, orzas, tazas, etc., siendo la loza estannífera de Madīnat al-Zāhra el paradigma del periodo ${ }^{46}$. El camino que siguió la técnica hasta llegar a al-Andalus no parece oscuro. Raqqada, en Túnez, fabricó con seguridad loza estannífera ya en el s. IX ${ }^{47}$. De hecho la Gran Mezquita de Qayrawan se decoró, entre 856 y 863, con azulejos de loza dorada, algunos importados y otros fabricados localmente por un artesano iraquí ${ }^{48}$.

46 Ibid.; B. MARTÍNEZ CAVIRÓ, op. cit., 1991.

47 A. DAOULATLI, "La production vert et brun en Tunisie du $\mathrm{IX}^{\mathrm{e}}$ au XII ${ }^{\mathrm{e}}$ siècle. Étude historique et stylistique", Le Vert \& le Brun, op. cit., 1997, pp. 69-89.

48 G. MIGEON, "Le décor lustré dans la céramique musulmane: à propos de publications récentes", Syria, 10 (1929), p. 130-136. 
La iconografía desarrollada en estas producciones presenta epigráficos como almulk, al'yumn o baraka (Fig. 1), la representación de temas asociados al Paraíso como los cuatro ríos, la flora, zoomorfos o antropomorfos evocadores de sus placeres -caballos, liebres, cervatillos (Fig. 2), gacelas, aves--, príncipes cazando o bebiendo (Fig. 3), o abstractos como el trenzado o nudo de la Eternidad. Debemos ver en ella la vinculación con el arte oficial, plasmado a través de estereotipos formales que de alguna manera definen ya una escuela estética y que se aplican indistintamente sobre pintura mural, miniatura, orfebrería, vidrio, tejido, o cualquier producción de elevada consideración social.

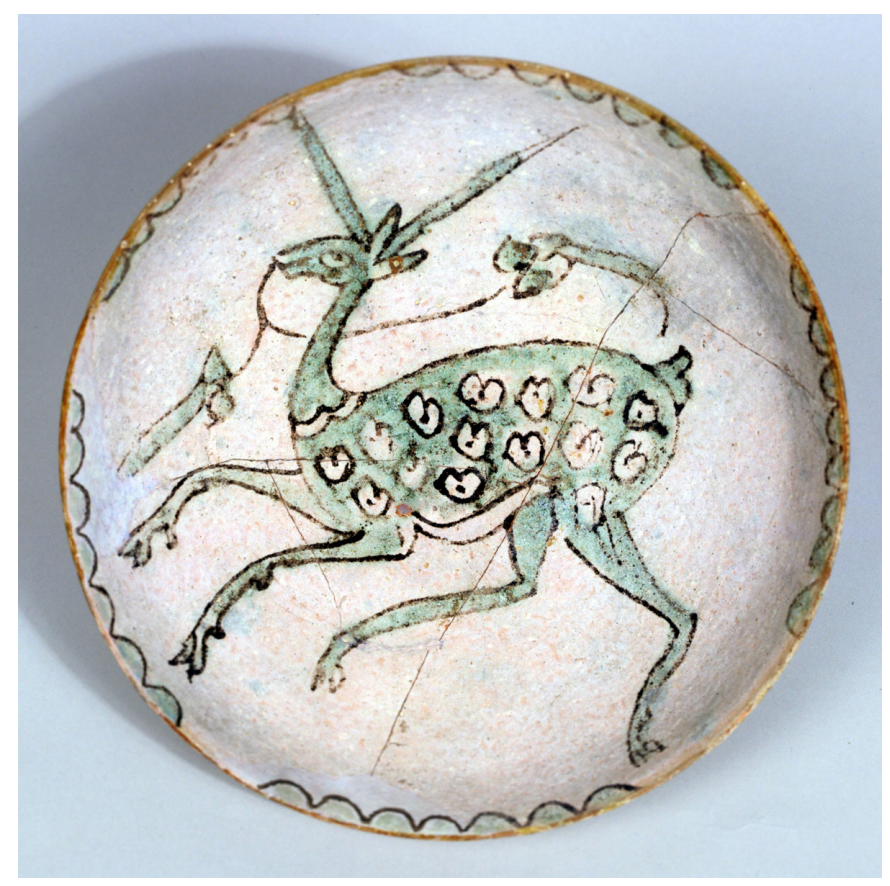

Fig. 2. Cuenco con vidriado estannífero que representa un cervatillo, s. X. Museo Nacional de Cerámica, inv. CE1/02858.

La proliferación de los reinos de taifas y su emulación de la corte califal, promocionó las artes y las ciencias al ser patrocinadas por los nuevos reyes, cobrando nueva vida la ciencia, la poesía, la arquitectura, la literatura o las artes decorativas. Como ejemplo de ello, podemos invocar el caso de Denia, ciudad que, convertida en capital de un reino de Taifas bajo Muyahid al-Muwaffaq (m. 1945), devino uno de los puntos centrales del comercio de al-Andalus con Egipto, norte de África, Sicilia y Oriente Medio, y fabricó una loza estannífera de calidad en la propia ciudad y en otras dependientes de alta relevancia política y estratégica, como Madināt Mayurqa en las Islas Baleares. Estas se independizaron como reino entre 1076 y 1116 continuando la misma política. Las exportaciones de lozas fabricadas en Mayurqa alcanzaron en la costa 


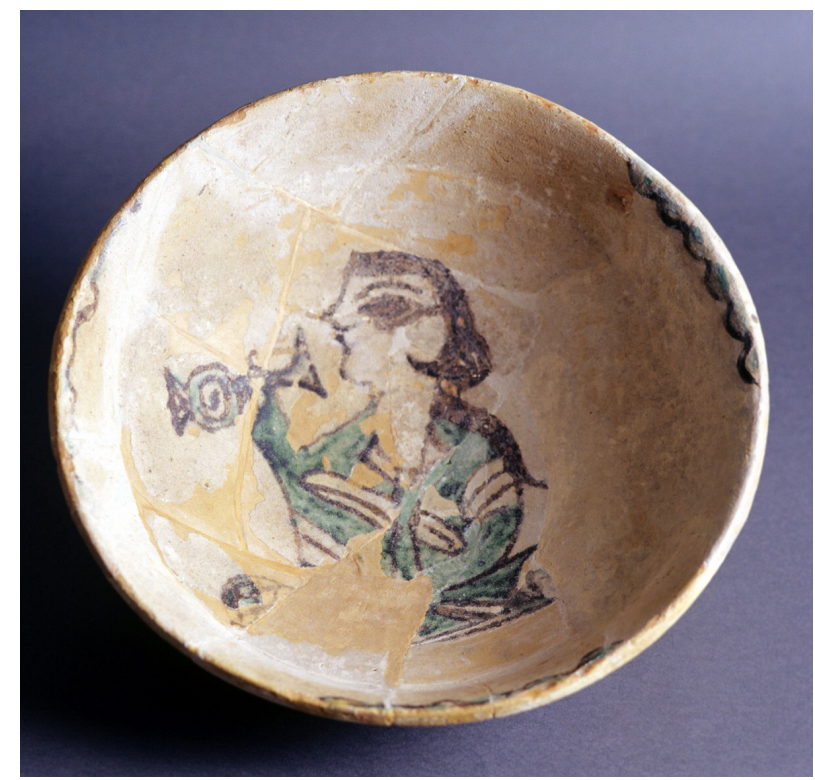

Fig. 3. Cuenco con vidriado estannífero hallado en Benetússer que representa un príncipe bebiendo, inicios del s. XI. Depósito del Ayuntamiento de Benetússer en el Museo Nacional de Cerámica.

mediterránea desde Torre de la Sal hasta la costa murciana y también se documentan en Pisa como objetos emblemáticos al ser colocados en la fachada de la iglesia de San Piero a Grado antes del $1048^{49}$. Denia fue conquistada por el rey taifa de Zaragoza en 1076, un importante espacio político surgido bajo la hegemonía de los Banū Tuyibī (1010-1040) continuado posteriormente por los Banū Hūd (1040-1110), pero la difusión de la ciudades productoras de estas lozas como centros hegemónicos o dependientes prosiguió hasta el dominio de al-Andalus por los almorávides que, por otra parte, nunca eliminaron la producción de esta técnica aunque cambiaron su nivel de representación al desproveerla de valor decorativo.

La naturaleza y propiedades de las lozas estanníferas andalusíes ya son conocidas gracias al hallazgo de varios talleres con sus desechos en Murcia, Zaragoza, Denia o Palma de Mallorca que han permitido avanzar en el conocimiento de las técnicas utilizadas $^{50}$. Las lozas estanníferas del yacimiento de San Nicolás (Murcia) se componen de un $10 \%$ de óxido de estaño, con cristales de casiterita uniformemente distribuidos en el vidrio y de tamaño pequeño, del orden de las 200-700 nm. Poseen una

49 G. BERTI, "I rapporti Pisa-Spagna (Al-Andalus-Maiorca) tra la fine del X ed il XV secolo testimoniati dalle ceramiche", Atti. XXXI Convegno Internazionale della Ceramica. Peninsola Iberica e Italia: rapporti e influenze nella produzione ceramica dal medioevo al XVII secolo, Florencia, 1999, pp. 241-253.

50 J. MOLERA et al., op. cit. (1999). Sobre los últimos hallazgos de talleres véase J. COLL y A. GARCÍA PORRAS, op. cit., 2010. Sobre la identificación de un alfar islámico y de su tecnología, J. COLL et al., "Hornos de cronología taifa de Palma de Mallorca: el yacimiento de la Calle Botons", Atti. XLII Convegno internazionale della ceramica, Albisola, 2010, pp. 7-24; también J. COLL et al., op. cit., 2012. 
composición mayor de plomo que las lozas mudéjares, compartiendo características con Palma y Denia. Los esmaltes estanníferos nazaríes del s. XIII presentan mayores cristales de casiterita y una distribución más heterogénea, mientras las producciones mudéjares vuelven a una distribución homogénea pero con cristales mayores (300$100 \mathrm{~nm}$ ), situación que se vuelve irregular desde el s. XIV en adelante.

La distribución homogénea de los cristales de casiterita parece relacionada con la realización de fritas estanníferas, bien documentadas en Murcia, Denia y Paterna por el hallazgo de crisoles destinados a realizar esta proceso de cocción del esmalte. Sin embargo, un mayor grosor o "marca" de la capa de esmalte y de cristales de estaño consigue una mejor opacificación. Por otra parte, el tamaño de los cristales de casiterita también se relaciona con la maduración del vidrio y una cocción más prolongada favorece cristales mayores, dominio alcanzado por los alfareros mudéjares. Finalmente, los problemas de desvitrificación y la aparición de las superficies pulverulentas que se interpretaban como engobes pueden deberse al exceso de plomo $(>57 \%)$ y a la falta de estabilizantes ${ }^{51}$. Para reducir el porcentaje de óxido de estaño se buscaba utilizar pastas claras, más calcáreas, o se decoloraba la superficie en la cocción del bizcocho mediante reducciones puntuales efectuadas a la mayor temperatura posible, de forma que el Fe libre quedara atrapado, por la formación de aluminosilicatos como la melilita o de piroxenos, decolorando el bizcocho.

Es general que el esmalte de estaño cubra el interior de las lozas estanníferas andalusíes mientras el exterior presenta solo vidriado de plomo. Esta característica prosigue hasta el s. XIII en las lozas mudéjares de centros como Teruel, pero pronto se abandona por reversos desnudos o totalmente cubiertos de estannífero por ambas caras en las lozas más costosas como la dorada o azul. El diferente gradiente de temperatura necesario para madurar correctamente cada vidriado hace que sea frecuente ver vidriados de plomo burbujeados o debilitados por el reverso, mientras los de estaño están correctos por el interior. De hecho, en el alfar taifa de Botons (Palma de Mallorca) se encontraron desechos con lozas estanníferas con el esmalte aún crudo, mientras el vidriado de plomo y los trazos realizados con pigmentos de cobre disueltos en vidriado de plomo para trazar la decoración estaban totalmente fundidos ${ }^{52}$.

Por otra parte, las lozas decoradas con cuerda seca se fabricaron simultáneamente a las grandes piezas estanníferas decoradas en verde y negro califales y taifas y representan una mayor complejidad técnica. La cuerda seca más antigua es la llamada cuerda seca parcial, caracterizada por una decoración que deja espacios de barro desnudo entre las zonas vidriadas. Se ha hallado en Pechina, Almería y en Madīnat al-Zahrā' ${ }^{53}$, en donde la presencia de epigráficos cúficos formales sobre cantarillas permite suponer que estas cerámicas ya jugaron un papel como objeto emblemático. La cuerda seca total se caracteriza por la presencia de vidriados de diferentes colores

51 J. MOLERA et al., op. cit. (1999), p. 26.

52 J. COLL et al., op. cit., 2010, p. 19.

53 R. CHAPOULIE et al., "Cuerda seca' ceramics from al-Andalus, Islamic Spain and Portugal (10th12th C. AD). Investigation with SEM-EDX and cathodoluminescence", Archaeometry, 47, 3 (2005), pp. 519534; C. DÉLÉRY, "La cerámica de cuerda seca de Madīnat al-Zahrā': descripción y propuesta de valoración histórica", Cuadernos de Madīnat al-Zahrā', 6 (2008), pp. 133-164. 


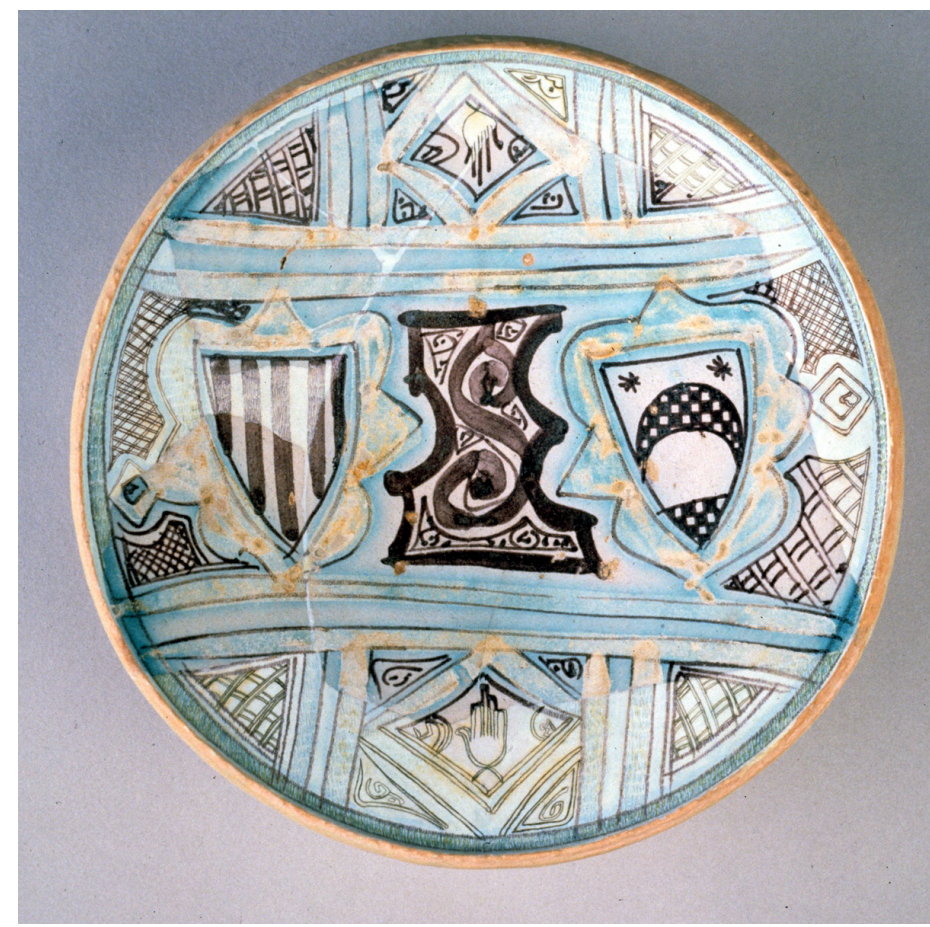

Fig. 4. Plato de Paterna, de producción mudéjar, con vidriado estannífero, que presenta los emblemas de Aragón y Luna alusivos al enlace matrimonial de Violante de Aragón con el conde Lope de Luna (1339). Museo Nacional de Cerámica, inv. CE1/00645.

sobre la misma pieza, yuxtapuestos y separados por una línea pintada de manganeso sin vidriar. En ellas solemos encontrar esmaltes de estaño junto a otros de plomo e incluso pigmentaciones que utilizan óxidos metálicos vertidos en masa en ambas bases. Ello hace que el ajuste en los puntos de fusión de las diferentes preparaciones vidriadas sea crítico confiriéndoles un valor singular. Por su parte, la fabricación de la cuerda seca total pertenece ya al s. XI, cuando alcanza su mayor calidad técnica.

La loza estannífera se fabricó en multitud de ciudades andalusíes, pero parece que durante el proceso de conquista impulsado por los reinos cristianos fueron paulatinamente rechazadas por la falta de un mercado habituado a su consumo. Sin embargo, en ciertas ciudades de la Corona de Aragón empezó su fabricación ya en el s. XIII, como ocurrió en Barcelona o en Teruel ${ }^{54}$, siendo ya un producto con cierta presencia comercial en el s. XIV y con valor de representación social al portar emblemas herál-

54 J. BELTRÁN DE HEREDIA, "Pisa arcaiga i vaixella verda al segle XIII. L'inici de la producció de pisa decorada en verd i manganès a la ciutat de Barcelona", QUARHIS, 3 (2007), pp. 138-159; J. ORTEGA, "Producción artesanal, transferencias comerciales y reproducción doméstica en Teruel, durante la Baja Edad Media (ss. XIII-XV)", Operis terre turolii. La cerámica bajomedieval en Teruel, Teruel, 2002, pp. 11-195. 


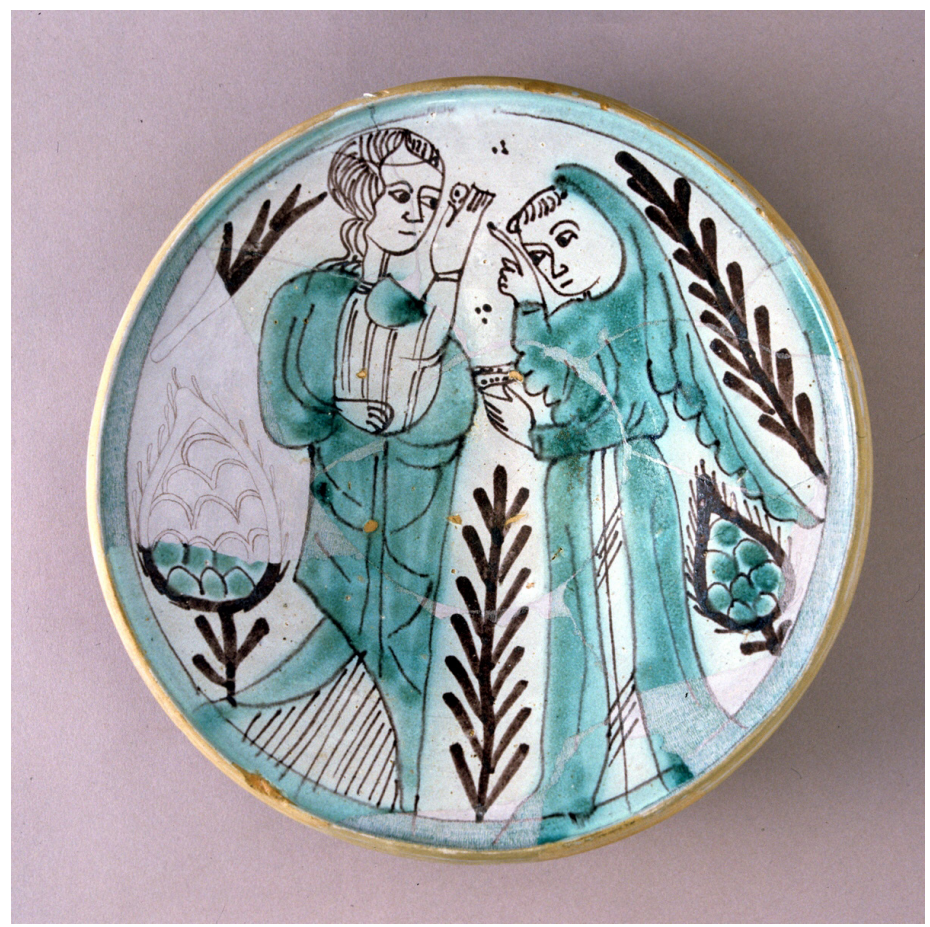

Fig. 5. Plato de Paterna, de producción mudéjar, con vidriado estannífero y representaciones humanas. Museo Nacional de Cerámica, inv. CE1/00648.

dicos, como los Aragón y Luna en Paterna (Fig. 4), o en Teruel ${ }^{55}$. Las decoraciones cristianas de los siglos XIII y XIV ofrecen temas de repertorio seriado, de carácter abstracto, con trazos paralelos, estrellas cenefas de eses, etc., y series con motivos que reproducen fielmente las decoraciones formales de artesonados, pintura parietal, miniatura o retablística, lo que hace pensar en que debieron trabajar en su ornamentación dos tipos de agentes: por un lado los alfareros y por otro dibujantes formados en claves estilísticas capaces de trazar a partir de modelos consensuados en una estética de carácter oficial formalizada aplicable a todo tipo de soporte. No se nos escapa este aspecto cuando vemos la calidad pictórica de los personajes representados en la loza verde y negra de Teruel, Paterna (Fig. 5) o Manises y la similitud que se aprecia con la ornamentación de artesonados como los de la Catedral de Teruel o la iglesia de la Sangre de Lliria.

Hemos comentado que en Oriente la proliferación de vidriados cerámicos se asocia con la difusión del llamado horno de barras. En al-Andalus parece que existe

55 J. COLL CONESA, "Evolución de la loza decorada de los siglos XIII al XIX. Focos, técnicas, producciones e influencias estilísticas. Visión global y desarrollo cronológico para un encuadramiento general", J. COLL (dir.), op. cit., 2011b, p. 8. 


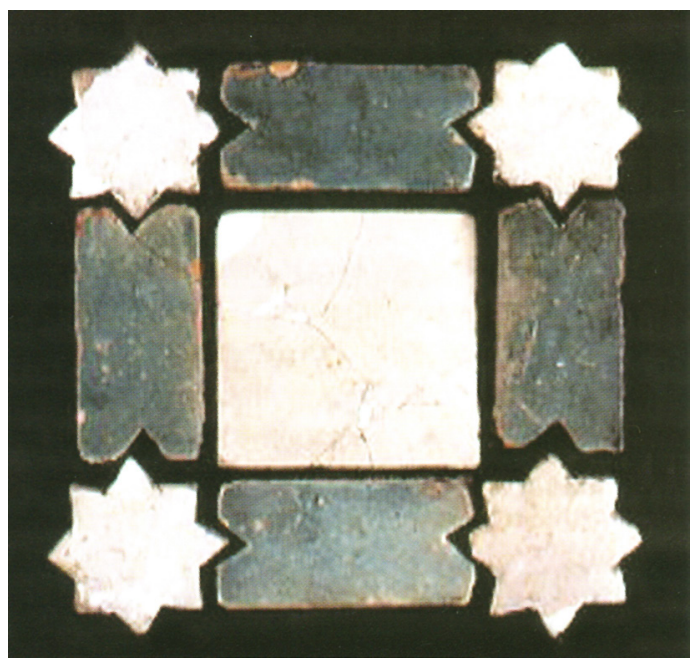

Fig. 6. Fragmento de alicatado con piezas de vidriado estannífero monocromo. Museo Nacional de Cerámica.

una clara asociación de esta estructura con la producción de loza estannífera en momentos tempranos ${ }^{56}$. Así, el horno localizado en la calle Ramón Ortega de Denia encerraba en una de sus gradas internas, producto de una reparación, un conjunto numeroso de lozas estanníferas pasadas de cocción $^{57}$. Seguramente permitían alcanzar una mayor temperatura en menor tiempo, pero fueron en general paulatinamente substituidos por hornos bicamerales de parrilla que facilitaban el control de la llama y el proceso de cocción ${ }^{58}$. A medida que la loza decorada ampliaba su mercado, los hornos aumentaban sus dimensiones hasta alcanzar un tamaño considerable durante la etapa mudéjar bajomedieval, necesario para cubrir una mayor demanda con una técnica de cocción más segura.

Debemos indicar que, en general, la decoración con óxidos metálicos de las lozas estanníferas solía hacerse sobre el vidrio antes de cocer. Sin embargo, al iniciarse la utilización del azul de cobalto se desarrolló la aplicación bajo cubierta, tanto sobre el bizcocho antes de la primera cocción, como tras esta ${ }^{59}$. Las lozas estanníferas, y especialmente la azulejería, pronto fueron requeridas por la realeza y la nobleza, como evidencian los encargos de alicatados multicolores de Jaime II, de Pedro el Ceremonioso o del conde de Ampurias para sus palacios y castillos (Fig. 6). Sin embargo, fue la azulejería decorada con azul cobalto la que alcanzó mayor significación áulica en

56 J. COLL CONESA y A. GARCÍA PORRAS, op. cit., 2010.

57 J.A. GISBERT, Cerámica califal de Dénia, Alicante, 2000.

58 J. COLL CONESA, "La producción cerámica medieval. Un balance entre el mundo islámico y el feudal. El caso del área valenciana”, A. GARCÍA PORRAS (ed.), Arqueología de la producción en época medieval, Granada, 2013, pp. 209-257.

59 Ibid., p. 251, y "El desarrollo técnico de la cerámica medieval. Visión transversal de las transferencias tecnológicas e innovaciones en los reinos cristianos peninsulares”, J. COLL (dir), op. cit., 2011, p. 46. 
las cortes de los reinos cristianos, al presentar emblemas heráldicos desde el último cuarto del s. XIV, continuando la moda iniciada por la decorada en verde y negro. Comandatarios de azulejos heráldicos en ese siglo fueron el papa Luna, el conde de Ampurias, Alfonso el Magnánimo y su esposa María de Luna, el duque de Berry Juan de Valois, y su hermano Felipe II de Borgoña.

\section{La loza dorada}

El Corán no indica ninguna prohibición (harām) en el uso de metales preciosos en la vajilla, aunque sí se da en diversas interpretaciones de textos coránicos, como los hadices autentificados de Al'Bujari o de Muslim. Así, según Ibn Umar, Al-Bayhaqī y Ad-Dāraqutnī transmitieron el hadiz que dice "El que bebe en un recipiente de oro o de plata, o en un recipiente que contiene oro o plata, tan solo traga del fuego del Infierno en su vientre". Otro hadiz sunní recoge que "el mensajero de Dios" dijo "No bebáis en recipientes de oro o plata y no os vistáis con brocados o sedas, ya que en este mundo son para ellos (los incrédulos) y para vosotros en el otro mundo, el Día de la Resurrección". También el Imam Al Ghazzali en el capítulo "Agradecimiento y alabanza" de su libro Ihiá "Ulum Al dín, manifiesta que "el mensajero de Dios" dijo "Quien come o bebe en utensilios de oro o plata está, ciertamente, llenando su estómago con fuego del Infierno". Estas y otras tradiciones orales y escritas abonan la necesidad religiosa de utilizar vajillas que no fueran de metales preciosos. Siendo así, la técnica de dorar vidrio, conocida previamente por los coptos en Egipto y luego usada en Damasco (Siria), parece que pudo servir de base técnica para el desarrollo de una loza que imitaba el metal precioso en la corte abasí del califato de Bagdad. La complejidad de su elaboración y su elevado precio, ya que en su fabricación entraban costosos y también preciosos componentes, además de requerir no menos de tres cocciones, la del bizcocho, la del esmalte y la del dorado, con pérdida de producto en cada una de ellas, pronto generaron su áurea mítica y la convirtieron en algo excepcional y por tanto codiciado, asociado a la imagen del poder y de la más alta representación simbólica en la escala social.

El dorado, técnicamente llamado reflejo metálico (barīq al-madenī), se origina en la transformación del óxido de cobre (verde) a cobre metálico (rojo). Para matizar y alterar su color y propiedades ópticas se le añaden al pigmento otros metales, entre ellos la plata o el oro. En su producción debemos distinguir dos técnicas básicas. Por un lado la reducción de un vidriado o esmalte que contiene óxidos metálicos susceptibles de ser transformados al estado de metal a través de gases reductores durante un proceso de combustión. Por otro, obedeciendo a un principio diferente, por el depósito sobre un vidriado de una fina capa metálica iridiscente de escaso grosor, también en atmósfera reductora. El primer procedimiento fue utilizado en China ya en el s. XI para la obtención del sang de boeuf o del rouge flambé, y consistía en añadir cobre a un vidriado para luego cocerlo en reducción. Se trata de una técnica que se preservó en Oriente Medio, redescubierta en Europa en el s. XVIII y reproducida sobre vidriados de plomo de forma habitual en Sevilla desde finales del s. XIX. En un vidriado de plomo requiere, al menos, una temperatura de unos $850^{\circ} \mathrm{C}$, que puede ser mayor 
en función de su formulación, con el fin de que los gases reductores alteren al propio vidriado para reducir el metal de cobre contenido en él. Se han hallado lozas musulmanas con vidriado verde de plomo y cobre que presentan accidentalmente manchas localizadas de color rojo, por efecto de falta de control de la combustión como resultado de la reducción parcial del vidriado. También se puede aplicar un esmalte y tras una primera cocción oxidante se provoca una reducción a menor temperatura que altere solo este y no el vidriado de soporte, técnica muy utilizada por los ceramistas para conseguir gran variedad de reflejos de diversos colores, practicada por Caiger Smith y por la saga Serra en su taller de Cornellà. Sin embargo este no fue el procedimiento habitual para la loza dorada medieval andalusí y mudéjar.

El segundo procedimiento, la deposición de una fina película metálica nanoestructurada en reducción, se documenta ya en el s. IX en Samarra. Esta es similar a la técnica descrita por Abu'l-Qasim entre las usadas en Kashan, con ingredientes y procedimientos muy semejantes a los conocidos de forma tradicional en Occidente, según vemos en los comentarios de Enrique Cock en referencia a Muel, formularios de Alcora del s. XVIII, el informe de Martínez de Irujo de 1785 y recopilaciones de Manises del s. XIX y XX ${ }^{60}$. Abu'l-Qasim comenta que se precisan $4,5 \mathrm{kgr}$ de oropimente (trisulfuro de arsénico), $3 \mathrm{kgr}$ de marcasita (sulfuro de hierro), 1,5 kgr de alúmina, y $250 \mathrm{gr}$ de cobre calcinado, que se muelen durante veinticuatro horas. 250 gr de esta mezcla se mezclan con 6 dirhams de plata y se calientan y muelen de cuatro a ocho horas, añadiéndosele vinagre. Con ello se puede ya decorar para luego cocer, en tercera cocción, durante setenta y dos horas a temperatura moderada ${ }^{61}$. También describe la técnica de reducción del vidriado, por la que se consigue el reflejo en segunda cocción con un significativo ahorro.

La técnica de la loza dorada documentada por la etnografía nos es trasmitida por M. González Martí ${ }^{62}$. Dice este autor que en el reflejo metálico los pigmentos han de llevar óxido de cobre "al que se adicionan otros óxidos, para que le presten escalas de tonalidades cromáticas, según la proporción de las medidas, y un medio que le lleve en suspensión". De hecho ya José Gestoso ${ }^{63}$ recordaba que ello había sido reconocido por Davillier, que afirmaba que el reflejo era un silicato de protóxido de cobre. También menciona que Riocreux y Carrand confirmaron que contenía plata y que las diferentes coloraciones se basaban en parte a la presencia de distintas proporciones de cobre y plata, más rojizas las primeras y más amarillentas las segundas, y también a la acción del fuego. Recientes estudios realizados con técnicas analíticas muy precisas, han confirmado estos resultados y explicado rigurosamente los procesos de formación de la decoración de la loza dorada monocroma o policroma que caracteriza las primeras producciones abásidas ${ }^{64}$.

60 J. PÉREZ CAMPS, La ceràmica de reflex metàl.lic de Manises, 1850-1960, Valencia, 1998.

61 Z. ROUHFAR y J. NEYESTANI, op. cit. (2008).

62 M. GONZÁLEZ MARTÍ, op. cit., 1944, pp. 318-329.

63 J. GESTOSO, Historia de los barros vidriados sevillanos desde los orígenes hasta nuestros días, Sevilla, 1903 (reed. 1995), pp. 277-302.

64 En la última década se ha avanzado enormemente en el conocimiento de los principios químicos que producen el reflejo metálico. Véase J. MOLERA et al., "Lustre recipes from a medieval workshop in Paterna, Archaeometry, 43, 4 (2001), pp. 455-460; J. PÉREZ-ARANTEGUI et al., "Luster pottery from the $13^{\text {th }}$ to the 
En la composición del pigmento de reflejo metálico utilizado en Valencia hasta hace pocos años intervenían el óxido de cobre, el almagre de Almazarrón (óxido de hierro), el óxido de plata y el sulfuro de mercurio o bermellón. Primero se cocían el cobre $(\mathrm{Cu})$ y la plata $(\mathrm{Ag})$ con azufre formando sulfuros, a lo que se añadía el almazarrón y el bermellón. Tras un largo molido y refinado se calcinaba la mezcla quedando los metales en estado de óxido y liberando al almazarrón de los carbonatos de cal y magnesio que lo acompañan. Tras un nuevo refinado se emulsionaba con vinagre para su aplicación, siendo usual pintar con una pluma de ave. Para producir reflejo debe luego cocerse en atmósfera reductora a una temperatura que oscila en función del punto de fusión del vidriado de base sobre el que se aplica -siempre algo por debajo para que los gases de reducción no lo afecten-, entre los $550^{\circ} \mathrm{C}$ y $650^{\circ} \mathrm{C}$.

Este reflejo tradicional se consigue en la tercera cocción y por ello es crítica, ya que mucho trabajo previo está en juego. Para controlar al máximo el resultado es muy importante el tipo de horno que se usa y el proceso de combustión, que debe ser reductor y bien pautado. En el Jowhar-nāme-ye Nezāmi (1196), un tratado persa sobre los metales que describe cómo hacer reflejo metálico, se llama al horno de dorar $d u d-d \bar{a} n$ o ahumador ${ }^{65}$. Generalmente el horno es de planta cuadrada y de tamaño pequeño, aún en la tradición vigente no suele superar el metro cúbico, por lo que ya se mencionaban con el diminutivo fornets de daurar en la documentación histórica del s. XVI. Los modelos etnográficos mantienen hornos con unas proporciones determinadas entre hogar y laboratorio, solo cinco entradas de gas en la parrilla del laboratorio o cámara de cocción, una central y cuatro en las esquinas, bóveda baja y una chimenea central en el techo, o alule, que debe estar debidamente proporcionada para favorecer el tiro reductor. Sobre los tiros esquineros se construyen cuatro columnas huecas hacia la bóveda, con aberturas contrapeadas abiertas hacia la cámara de combustión para que los gases salgan con una distribución uniforme en todos los niveles y

$16^{\text {th }}$ century: a nanostructured thin metallic film", Journal of the American Ceramic Society, 84, 2 (2001, pp. 442-446; J. MOLERA et al., "La céramique à reflets métalliques: une approche technique", Le Calife, le prince et le potier : Les faïences à reflets métalliques, Lyon, 2002, pp. 214-219; A.D. SMITH et al., "MicroEXAFS study into the oxidation states of copper coloured Hispano-Moresque lustre decorations", Journal de Physique IV, 104 (2003), pp. 19-522; O. BOBIN et al., "Coloured metallic shine associated to lustre decoration of the glazed ceramics: a theoretical analysis of the optical properties", Journal of Non-Crystalline Solids, 332 (2003), pp. 28-34; O. BOBIN et al., "The role of copper and silver in the colouration of metallic lustre decoration (Tunisia - 9th century, Mesopotamia - 10th century, Sicily - 16th century). A first approach", Color Research and Application, 28, 5 (2003), pp. 352-359; J. MOLERA et al., "The role of cinnabar in Middle Age lustre pottery production technology: an X-ray Diffraction investigation", Journal of the American Ceramic Society, 79, 6 (2004), pp. 1018-1023; T. PRADELL et al., "Ionic exchange mechanism in the formation of medieval lustre decorations", Journal of the American Ceramic Society, 88, 5 (2005), pp. 1281-1289; M. SCHVOERER, C. NEY y P. PEDUTO (eds.), Décor de lustre métallique et céramique glaçurée, Ravello, 2005; J. ROQUE et al., "Evidence of nucleation and growth of metal $\mathrm{Cu}$ and $\mathrm{Ag}$ nanoparticles in lustre: AFIM surface characterisation, Journal of Non-Crystaline Solids, 351 (2005), pp. 568-575; T. PRADELL et al., "Technology of Islamic Lustre", Journal of Cultural Heritage, 9 (2008), pp. 123-128; y M. VENDRELL et al., "La cerámica de reflejo dorado: una aproximación técnica a la nanotecnología medieval", I Congreso Internacional Red Europea de Museos de Arte Islámico, Granada, 2012, pp. 237-450.

65 Y. PORTER, "Les techniques du lustre métallique d'après le Jowhar-Nâme-Ye Nezâmi (1196 AD)", C. BAKIRTZIS (ed.), Actes du VIIe Congrès International sur la Céramique Médiévale en Méditerranée, Atenas, 2003, pp. 427-436. 
conseguir una atmósfera reductora lo más homogénea posible en el laboratorio. Para asegurar la calidad de la combustión, la cocción se conduce usando leña que por sí misma produce gases reductores, como plantas aromáticas que contienen hidrocarburos naturales, en general el romero, aunque es apta cualquier especie que cumpla esta condición, sea menuda y esté preferiblemente seca. Durante la combustión, conducida empíricamente, hay que observar el comportamiento de los gases y las evidencias que manifiesta el horno cuando alcanza cada nivel de temperatura. En el momento en que se considera que el final está próximo, se van extrayendo por la chimenea, una tras otra, unas pequeñas muestras de fragmentos con el mismo vidriado y pigmento hasta que manifiestan el punto de ajuste óptimo. Tras ello se deja enfriar el horno para luego sacar la cerámica que debe ser lavada para eliminar un residuo superficial llamado cosela, que servirá para la preparación del siguiente pigmento. Este proceso no deja resquicio al azar y ha sido practicado durante generaciones para asegurar el resultado final. Incluso una de las fórmulas de reflejo de 1749 de la Real Fábrica de Alcora trasmite esta información de forma bastante exacta para que la combustión pueda ser realizada por un profano.

En cuanto a las referencias históricas que tenemos sobre producción de loza dorada en al-Andalus, sabemos que durante el califato de Córdoba solo se importó. Las lozas doradas halladas en Madīnat al-Zahrā' han sido atribuidas a centros iraquíes por su semejanza material con producciones de $\mathrm{Susa}^{66}$, aunque previamente se había indicado un claro parecido estilístico con cerámicas contemporáneas producidas en Egipto bajo el gobierno de los ikhshidíes (935 a 969), dependiente de los abasíes ${ }^{67}$.

La fabricación fue iniciada en los reinos de taifas, mulāk al-tawā’ if, y proceden de la taifa de Sevilla las piezas más antiguas. El médico cordobés Abu Al-walid Marwan ibn Janah (990-1050) nos habla que alfareros del este han enseñado nuevas técnicas y que producen con materias locales piezas con estilos importados. Ello evidencia que, al contrario de lo manifestado hasta ahora, este periodo no es una época de decadencia, sino al contrario, especialmente por la descentralización del poder en multitud de cortes que emularon, e incluso potenciaron y multiplicaron, sus acciones de representación a través del impulso de las artes y las ciencias. En palabras de Robinson "Con el ánimo de legitimar su poder recién adquirido, los reyes de taifas pretendieron no solo adueñarse de parte de la gloria del califato emulando los prototipos cordobeses, sino también responder a las expresiones panislámicas del arte cortesano más recientes y refinadas" 68 .

Existen al menos cuatro grandes áreas productoras de loza dorada andalusí. La evidencia cronológica más antigua procede del foco de Sevilla, con hallazgos del propio Alcázar en el que un cuenco porta una inscripción relativa al malik abadí Al-Mu'tadīd (r. 1041-1069). El nombre de su sucesor al-Mu'tamid (r. 1088-1091) se encuentra en

66 A. POLVORINOS DEL RÍO et al., "Estudio arqueométrico de la loza dorada de Madinat al-Zahra, Córdoba", Cuadernos de Madīnat al-Zahrā', 6 (2008), pp. 165-179.

67 A. HEIDENREICH, "La loza dorada medieval en la Península lbérica. Aportaciones recientes a su evolución y nuevos datos para su cronología”, Anales de Arqueología Cordobesa, 18 (2007), pp. 401-423.

68 C. ROBINSON, "Las artes en los reinos de taifas", Al-Andalus. Las artes islámicas en España, Madrid, 1992, pp. 49-61. 


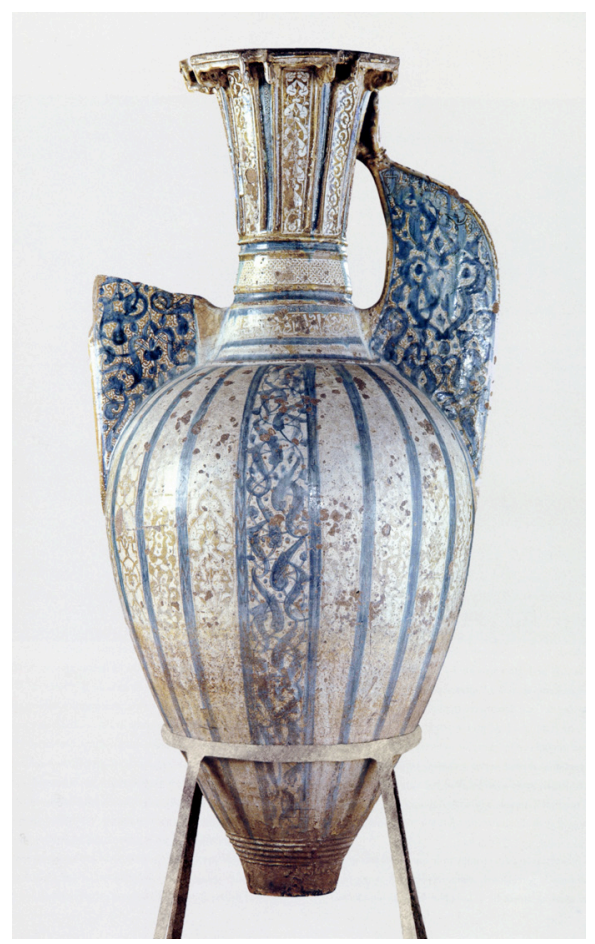

Fig. 7. Jarrón de la Alhambra hallado en Hornos. Loza estannífera decorada en azul de cobalto y reflejo metálico. Museo Arqueológico Nacional, Madrid.

otras piezas. Otro núcleo, cuya producción se centra antes del 1118, se ha identificado en Zaragoza y el valle del Ebro, siendo el posible origen de talleres regionales mudéjares que producen a lo largo del s. XII. A partir de estas fechas la arqueología ha evidenciado otros alfares en Almería, Málaga, Granada, Murcia, Cieza, Mértola o Calatrava ${ }^{69}$ y son bien conocidas las citas de al-Idrisi (m. 1164-1165), al-Zuhri (s. XII), al Himyarí (m. 1326), Ibn Said (1213-1286), al-Maqqarī, al-Umarī y Ibn Fadl Allāh (1337), Ibn Batūta (1356), Ibn al-Jatib (1313-1374) que hablan de loza dorada andalusí.

La loza dorada previa a los almohades tuvo una difusión limitada, con ejemplares exportados, por ejemplo, al área toscana o ligur, pero también a Centroeuropa o norte de África ${ }^{70}$ desde el s. XII. Se encuentra relacionada con ambientes áulicos o con residencias de personajes de relevancia social tanto en el ámbito urbano como rural.

69 A. HEIDENREICH, "La loza dorada temprana en el ámbito Mediterráneo y la implementación de la nueva técnica en la Península Ibérica - una aproximación”, I Congreso Internacional Red Europea de Museos de Arte Islámico, Granada, 2012, p. 271.

70 M. ROSSER-OWEN, “'From the Mounds of Old Cairo': Spanish ceramics from Fustat in the collections of the Victoria and Albert Museum", I Congreso Internacional Red Europea de Museos de Arte Islámico, Granada, 2012, pp. 163-187. 


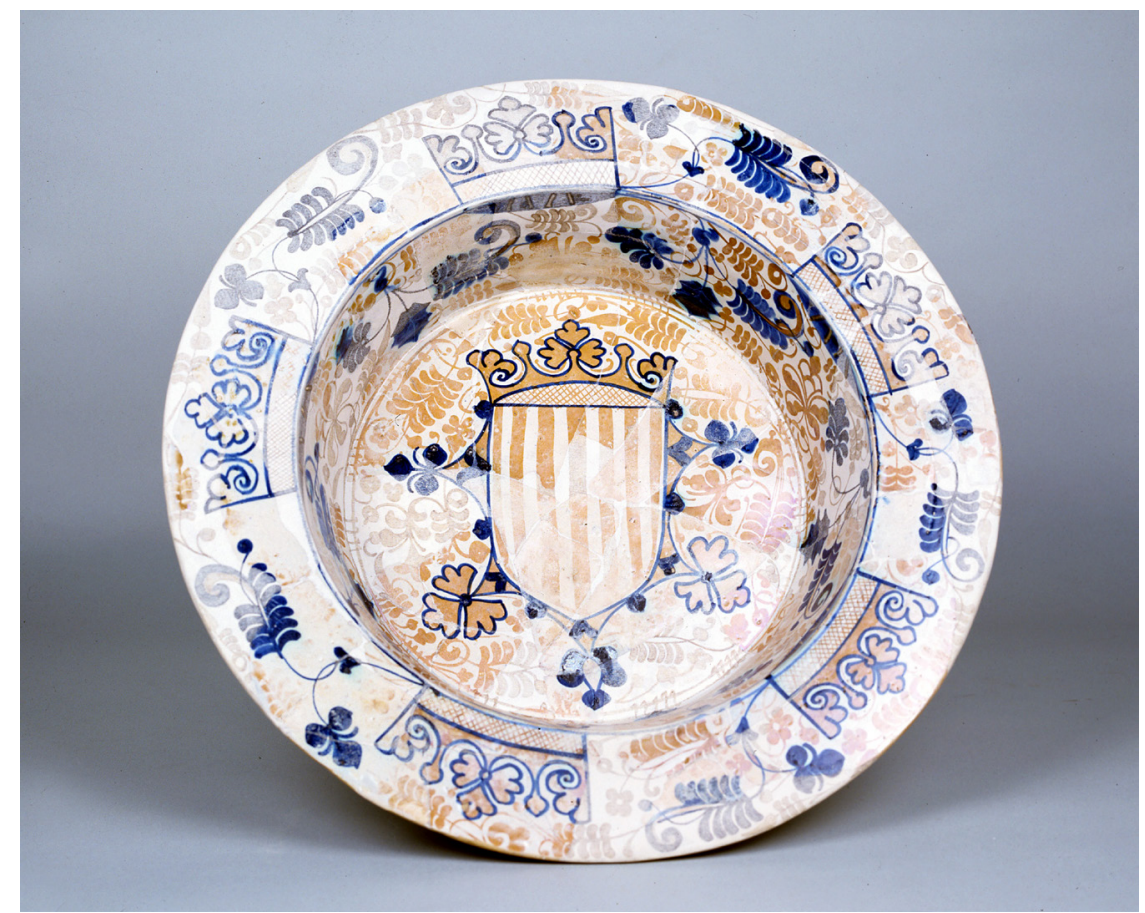

Fig. 8. Plato hondo, loza estannífera decorada en azul de cobalto y reflejo metálico con el escudo del reino de Aragón. Museo Nacional de Cerámica, inv. CE1/01554.

Al-Idrisi aclara cómo se llamaba a estas lozas doradas al mencionar un "guidār mudhahhab" o plato dorado, ya que guidār o al-guidār, como en portugués, y tabak, son los vocablos andalusíes documentados por fuentes escritas referidos a este objeto ${ }^{71}$.

Sin embargo, la difusión se ampliará con una verdadera distribución comercial destinada al mercado de la burguesía emergente en el s. XIII a través de las redes de comerciantes ligures y toscanos ${ }^{72}$. Esta será la misma que fomentará, en el siglo siguiente, que los magnates impulsen la instalación de alfares mudéjares en Manises y Paterna (Valencia) para realizar prestigiosas cerámicas que la propia documentación mercantil denominará "malagueña", "obra de Málica" u "operis terre picte Manizes consimilis operis Maleche" (1326) $)^{73}$, en una competencia directa con las cerámicas nazaríes que compartirán cargamentos mientras desde la corte granadina se siguen realizando obsequios de embajada con elementos suntuarios de valor extraordinario

71 A. FILI, "Quelques aspects de la céramique médiévale d'après les textes arabes", Cerámica Medieval e Pós Medieval. Métodos e resultados para o seu estudo, Tondela, 1997, pp. 399-406.

72 A. GARCÍA PORRAS y A. FÁBREGAS GARCÍA, "Genoese trade networks in the southern Iberian peninsula: trade, transmission of technical knowledge and economic interactions", Mediterranean Historical Review, 25, 1 (2010), pp. 35-51.

73 J. COLL CONESA, "Aspectos técnicos, formales y decorativos de la loza dorada de Manises. Las series iniciales”, I Congreso Internacional Red Europea de Museos de Arte Islámico, Granada, 2012, pp. 311-343. 


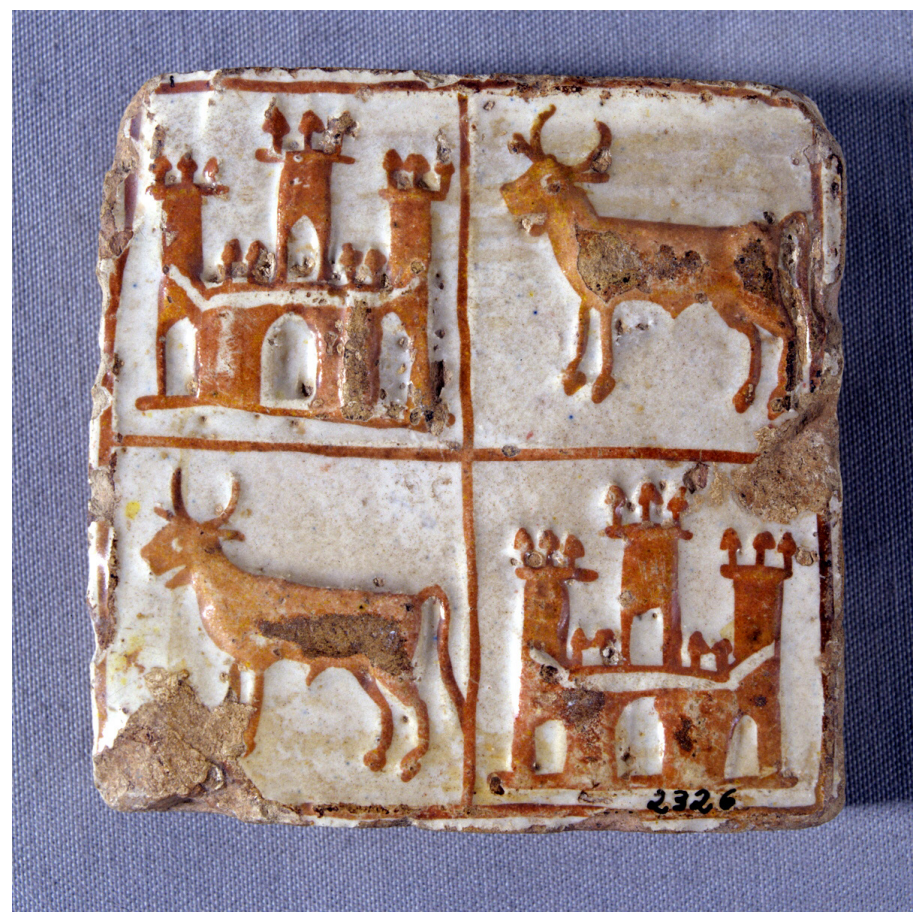

Fig. 9. Azulejo estannífero con reflejo metálico, con el escudo de la familia Boil, señores de Manises. Museo Nacional de Cerámica, inv. CE1/02326.

como los vasos de la Alhambra que de ese modo llegaron a Sicilia (Mazzara del Vallo o Palermo) (Fig. 7) y a Fustat ${ }^{74}$. La loza dorada valenciana alcanzará una gran difusión en el s. XIV, especialmente la de Manises, como recuerda fra Francesc Eimenis en su Regiment de la Cosa Pública, en 1383. Pero será en el s. XV cuando la loza dorada se convertirá en un elemento codiciado en los reinos cristianos de Europa y será usada como soporte emblemático de instituciones (Fig. 8), individuos poderosos (Fig. 9), ricos mercaderes y prelados cuya heráldica presidirá los propios platos, tarros o jarrones. Así, desde hasta la reina María de Castilla o Alfonso el Magnánimo, Felipe el Bueno de Borgoña (Fig. 10), el delfín de Francia, Blanca de Anjou, los Reyes Católicos, y también numerosos mercaderes toscanos o Piero il Gotoso Medici, entre muchos otros, gozarán del privilegio de disponer en su aparadores de grandes platos de loza dorada de Manises, pero eso será poco antes de que llegue su declive provocado por la calidad, novedad y pujanza de la loza polícroma renacentista italiana ${ }^{75}$.

74 B. MARTíNEZ CAVIRÓ, op. cit., 1991, y La loza dorada del Instituto Valencia de Don Juan. Oro y Lapislázuli, Valencia, 2010, y "La loza dorada y los Jarrones de la Alhambra”, C. YUSTI (coord.), Los Jarrones de la Alhambra, simbología y poder, Madrid, 2006, pp. 45-58; J. ZOZAYA, "Los jarrones de la Alhambra: función, significado y cronología", ibid., pp. 35-44.

75 J. COLL CONESA, op. cit., 2011b, p. 18. 


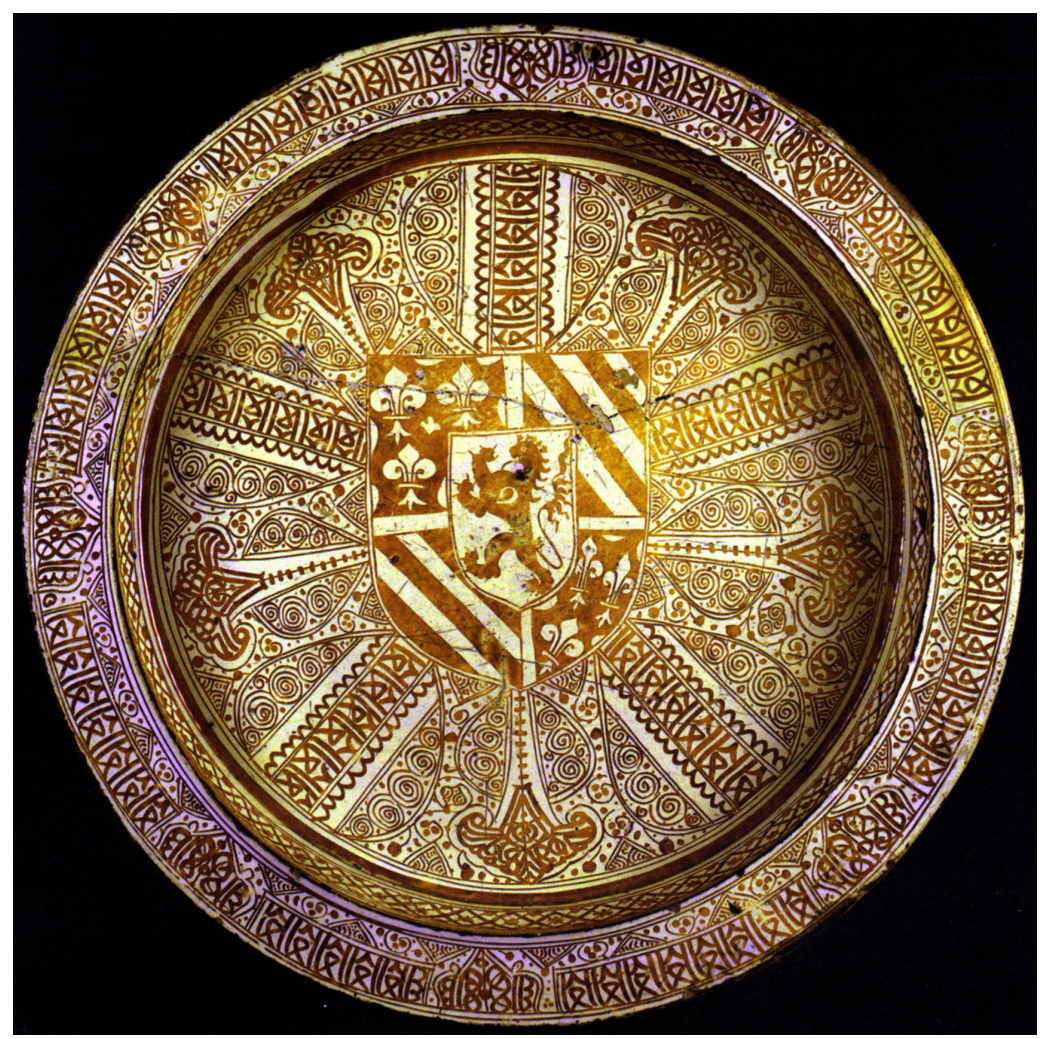

Fig. 10. Gran bandeja de loza estannífera decorada en reflejo metálico con el escudo de Felipe el Bueno, duque de Borgoña. Museo Lázaro Galdiano (Madrid).

\section{A modo de conclusión}

El Islam desarrolló la cerámica como un elemento estético con valor de representación social y política, especialmente desde la fundación del califato abasí de Bagdad. Esta capacidad se consiguió por los complejos conocimientos tecnología y experiencia empírica que desarrollaron los propios alfareros, siendo su trabajo reconocido y apreciado socialmente y claramente impulsado por los talleres palatinos. Determinadas especialidades técnicas cerámicas, como la loza estannífera policroma y especialmente la loza dorada, jugaron un evidente papel áulico al servicio del poder. Ello queda patente a través de la arqueología por su hallazgo en los centros de poder y decisión política como la ciudad palatina de Madīnat al-Zahrā', el Alcázar de Sevilla, la Alfajería de Zaragoza, la Alcazaba de Almería, la Alcazaba de Onda, y también en ámbitos urbanos y rurales de relevancia social. A medida que los reinos cristianos peninsulares se constituían en entidades de poder, necesitadas también de una organización de representación, emularon el refinamiento de las cortes islámicas. Al principio 
adquirían bienes suntuarios manufacturados en al-Andalus, pero pronto impulsaron un artesanado mudéjar que transmitió a los nuevos espacios políticos el gusto por estas producciones y sus técnicas, al tiempo que paulatinamente la incipiente burguesía mercantil extendía el consumo de estos bienes a cada vez más estamentos sociales. El s. XV significó el canto del cisne de las técnicas cerámicas iniciadas por el Islam, la loza estannífera y la técnica del reflejo metálico, cuando ya alcanzaban su mayor aprecio entre las jerarquías cristianas. Pero el prestigio y la estima por aquella cerámica más compleja y técnicamente avanzada -la nueva policromía renacentista y la porcelana y sus imitaciones- se mantuvieron en la sociedad europea hasta el fin de la modernidad. 